\title{
A LOCAL SCALE MODELING STUDY OF MERCURY DEPLETION EVENT
}

\section{AT CANADIAN ARCTIC}

\author{
Minesh Panchal, B.Eng. \\ The Maharaja Sayajirao University of Baroda \\ Baroda, India, 1994
}

A thesis

presented to Ryerson University

in partial fulfillment of the

requirements for the degree of

Master of Applied Science

in

Chemical Engineering

Toronto, Ontario, Canada, 2004

CMinesh Panchal, 2004 
UMI Number: EC53415

\section{INFORMATION TO USERS}

The quality of this reproduction is dependent upon the quality of the copy submitted. Broken or indistinct print, colored or poor quality illustrations and photographs, print bleed-through, substandard margins, and improper alignment can adversely affect reproduction.

In the unlikely event that the author did not send a complete manuscript and there are missing pages, these will be noted. Also, if unauthorized copyright material had to be removed, a note will indicate the deletion.

\section{UMI}

UMI Microform EC53415

Copyright 2009 by ProQuest LLC

All rights reserved. This microform edition is protected against unauthorized copying under Title 17, United States Code.

ProQuest LLC

789 East Eisenhower Parkway

P.O. Box 1346

Ann Arbor, MI 48106-1346 


\section{Author's Declaration}

I hereby declare that I am the sole author of this thesis.

I authorize Ryerson University to lend this thesis to other institutions or individuals for the purpose of scholarly research.

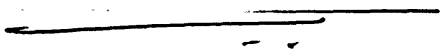

I further authorize Ryerson University to reproduce this thesis by photocopying or by other means, in total or in part, at the request of other institutions or individuals for the purpose of scholarly research.

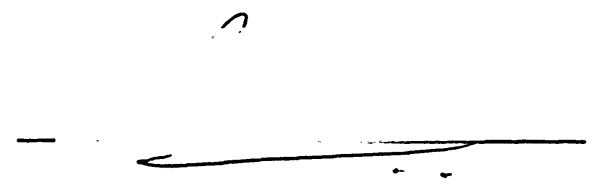




\section{Borrower's Page}

Ryerson University requires the signatures of all persons using or photocopying this thesis. Please sign below, and give address and date.

\begin{tabular}{|c|c|c|c|}
\hline Name & Signature & Address & Date \\
\hline & & & \\
\hline & 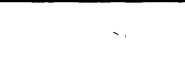 & & \\
\hline & & & \\
\hline & & & \\
\hline & & & \\
\hline & & & \\
\hline & & & \\
\hline & & & \\
\hline & & & \\
\hline & & & \\
\hline & & & \\
\hline & & & \\
\hline & & & \\
\hline & & & \\
\hline & & & \\
\hline & & & \\
\hline & & & \\
\hline
\end{tabular}




\section{A LOCAL SCALE MODELING STUDY OF \\ MERCURY DEPLETION EVENT AT CANADIAN ARCTIC}

By Minesh Panchal

Master of Applied Science in Chemical Engineering, Ryerson University, 2004

\section{ABSTRACT}

A modeling study was conducted on the transformation and deposition patterns of atmospheric mercury in the Canadian Arctic. One Dimensional (1-D) local scale model was used to simulate the episodic depletions of gaseous elemental mercury (GEM) after polar sunrise at Alert, Canada. The model was developed by starting with existing meteorological model (LCM-Local Climate Model) which is coupled with Canadian Aerosol Module (CAM) and then adding modules specific to atmospheric mercury chemistry. The model is able to simulate local scale transport of mercury over the entire depth of the troposphere with a basic time step of $20 \mathrm{~min}$. and incorporates current knowledge of transformation reactions of atmospheric mercury species. Three mercury species $\mathrm{Hg}(0), \mathrm{Hg}(\mathrm{II})$ and $\mathrm{Hg}(\mathrm{p})$ were considered. The developed model was applied to a portion of the Canadian arctic region, Alert, for the month of April 2002. The model was then evaluated by comparing model estimates of mercury species concentrations with the measurement data collected in the Canadian arctic by Meteorological Services of Canada, Downsview, Ontario. The results from this modeling study agree reasonably well with some underestimation caused by lower conversion of gaseous elemental mercury (GEM) into reactive gaseous mercury (RGM) and subsequent conversion to total particulate mercury (TPM). A sensitivity analysis was also conducted to examine the depositions of mercury species in response to changes in ozone and soot concentrations. 


\section{Acknowledgements}

I would like to thank my supervisor Dr. Julia Lu for her strong support and insightful guidance during my graduate study at Ryerson University.

My deep thanks also goes to Dr.Sunling Gong, Dr.Ashu Dastoor, Dr. Ping Huang and Mr. Davignon at Meteorological Services of Canada for providing me source code of existing model and advising on its modification. I would also like to thank to Alexandra Steffen at Meteorological services of Canada for providing experimental data.

Finally, I would like to thank all my fellow graduate students and family members for their support and encouragement.

This study was jointly supported by Ryerson University, Department of Chemistry, Biology and Chemical Engineering and Meteorological Services of Canada, Downsview, Ontario. 


\section{Table of Contents}

Author's Declaration...................................................................ii

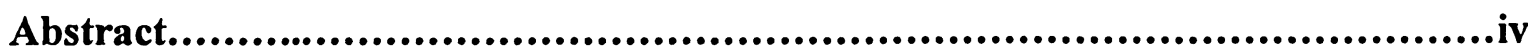

Acknowledgements.........................................................................v

Table of Contents......................................................................vi

List of Tables........................................................................... ix

List of Figures..........................................................................

Chapter 1 Introduction.............................................................. 1

Chapter 2 Literature Review....................................................... 5

2.1 Introduction..................................................... 5

2.2 Sources and emissions................................................ 7

2.3 Forms of mercury in atmosphere................................... 9

2.4 Atmospheric transformations and removal processes................. 10

2.5 Mercury cycling in the environment............................... 12

2.6 Local sources vs. long range transport.............................. 15

2.7 Atmospheric mercury chemistry.................................... 16

2.8 Mercury and human health........................................ 17

2.9 Modeling of the transport and transformation of atmospheric $\mathrm{Hg}$......... 18

2.10 Mercury measurements in the Arctic............................... 20

2.11 Arctic mercury depletion.......................................... 21

Chapter 3 Model Development........................................................ 23

3.1 Introduction....................................................... 23

3.2 Model development 23

3.2.1 Canadian Aerosol Module (CAM) ........................... 23

3.2.2 General Structure of LCM....................................... 26 
3.2.3 Mercury Chemistry Module................................. 27

3.3 Model implementation............................................. 32

Chapter 4 Local Scale Transport, Transformation and Deposition of Atmospheric Mercury : A Simulation Study......................... 35

4.1 Introduction................................................... 35

4.2 Simulation procedure........................................... 35

4.2.1 Procedure.................................................. 35

4.2.2 Location of simulation...................................... 35

4.2.3 Model inputs............................................. 36

4.2.4 Sample collection and analysis............................. 37

4.2.5 Simulation outputs............................................ 39

4.3 Simulation results................................................ 40

4.3.1 Ambient concentrations of mercury species.................... 40

4.3.2 Ratio of RGM/GEM, PM/GEM and PM/RGM................ 42

4.3.3 Dry deposition................................................ 44

4.3.4 Wet deposition.......................................... 45

Chapter 5 Sensitivity Analysis..................................................... 46

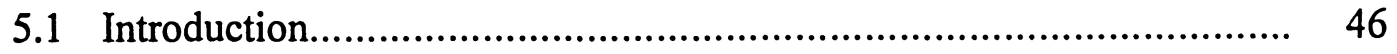

5.2 Sensitivity analysis........................................... 46

5.3 Results of sensitivity analysis....................................................... 47

5.3.1 Dry deposition............................................................... 47

5.3.2 Wet deposition................................................................ 48 


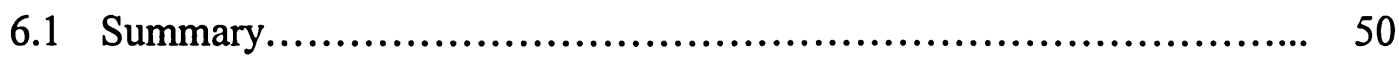

6.2 Concluding remarks............................................ 50

6.3 Regulation concern........................................... 51

6.4 Recommendations for future work.............................. 52

References................................................... 53

Appendix A Reaction rate constant for mercury chemistry used in $\quad 59$ modeling 


\section{List of Tables}

Table 2.1 Physical/chemical properties of mercury and some of its compounds

Table 2.2 Estimated Hg emissions from anthropogenic sources in the U.S.

Table 2.3 Typical concentrations of mercury species in the atmospheric environment

Table 2.4 $\mathrm{Hg}$ concentrations in air and $\mathrm{Hg}$ in rain samples

Table 5.1 Conditions used in sensitivity study 


\section{List of Figures}

$\begin{array}{lll}\text { Figure 2.1 Atmospheric mercury cycle } & 13\end{array}$

$\begin{array}{lll}\text { Figure 2.2 Mercury cycling pathways in aquatic environments } & 14\end{array}$

$\begin{array}{lll}\text { Figure 3.1 CAM general structure } & 24\end{array}$

Figure 3.2 Mercury chemistry scheme used in 1-D Model . 28

$\begin{array}{lll}\text { Figure } 3.3 \quad \text { Column model for mercury } & 33\end{array}$

$\begin{array}{lll}\text { Figure 4.1 Location of simulation } & 36\end{array}$

Figure 4.2 Automated Tekran $2537 \mathrm{~A} \mathrm{Hg}^{0}$ analyzer with $1130 / 1135$ speciation 38 systems

Figure 4.3 Observed concentration of GEM,RGM and PM 39

Figure 4.4 Simulated and observed reactive gaseous mercury concentration 40

Figure 4.5 Simulated and observed particulate mercury concentration 41

Figure 4.6 Simulated and observed ratio of RGM/GEM 42

Figure 4.7 Simulated and observed ratio of PM/GEM 43

Figure 4.8 Simulated and observed ratio of PM/RGM 44

$\begin{array}{lll}\text { Figure 5.1 RGM Dry deposition for the base case and conditions listed in } & 47\end{array}$ Table 5.1

Figure 5.2 PM Dry deposition for the base case and conditions listed in $\quad 48$ Table 5.1

Figure 5.3 Wet deposition for the base case and conditions listed in Table 5.1 


\section{Chapter 1}

\section{Introduction}

Mercury $(\mathrm{Hg})$ is one of the major pollutants in the Arctic environment, and there is evidence of increasing concentrations especially in the marine ecosystems over time (Arctic Monitoring and Assessment Programme, 1998). The mercury problem is also in many ways linked to the overall air pollution situation. Mercury is often treated separately from other heavy metals in scientific investigations and environmental pollution assessments. This is mainly due to the different chemical and physical properties of mercury, compared to other metals. Since the recognition of the environmental effects of mercury, the use of the metal has decreased in many countries and legislation has been imposed in order to diminish the negative effects (Munthe 1993).

The concern about mercury pollution in the arctic is mainly due to elevated methyl mercury levels in the arctic ecosystem and the health effects caused by methylated mercury through consumption of fresh water and marine fish (Lin and Pehkonen 1999). It is generally believed that atmospheric deposition of mercury is a major source of elevated mercury concentrations in fish in numerous rivers and lakes ( $\mathrm{Lu}$ et al. 2001, Pirrone et al. 1995). Inorganic forms of mercury released into the environment can be converted through chemical and biological processes, into the highly toxic methyl mercury ( $\mathrm{MeHg}$ ) species. The ability of $\mathrm{MeHg}$ to bio-concentrate more than a million-fold in the aquatic food chain is the main reason for concern about the emissions/mobilization of mercury into the biosphere (Schroeder and Munthe 1998). 
Each year, about $6000-7500$ tons of mercury $(\mathrm{Hg})$ is emitted into the atmosphere, of which $50-75 \%$ is related to human activities, and the rest is emitted from various natural surfaces including bedrock, water, soil and vegetation (Fitzgerald 1995). The majority of the current emissions from natural surfaces are the result of mercury deposited to the surfaces from industrial activities over the past century (Stein et al. 1996).

A process known as "mercury depletion" compounds the problem of mercury contamination in the Arctic. High Concentrations of mercury found in the High Canadian Arctic, an area with no significant sources of mercury, may be linked to the long-range transport of mercury. Mercury, like other semi-volatile compounds participates in a global distillation phenomenon that transfers it from equatorial, subtropical and temperate regions to the Polar Regions via the "grasshopper effect". When this phenomenon takes place, emitted mercury re-enters the atmosphere by volatilizing after initial deposition, and continues over time to "hop" through the environment in the direction of prevailing winds, favoring accumulation in the colder regions of the planet. During the summer months, major air currents in the Northern hemisphere lead to the arctic, and once there, mercury can no longer gain heat energy for another "hop" out of the Arctic. The net result is an accumulation of mercury in the Arctic with few emission sources in the region (http://www.ec.gc.ca/mercury 2003).

The discovery of the springtime mercury depletion events (MDE) at Alert in the Canadian Arctic stimulated a vigorous research effort in six circumpolar nations and other countries with a keen interest in preventing pollution of Polar Regions (Schroeder 
et al. 1998). Schroeder et al. discovered that following polar sunrise in the spring, atmospheric $\mathrm{Hg}^{0}$ can be rapidly oxidized to the reactive and water-soluble forms of $\mathrm{Hg}^{2+}$, greatly enhancing the wet and dry deposition flux of this heavy metal to the fragile biosphere. This reaction is thought to occur photo chemically (in the presence of sunlight) and in the presence of reactive chemicals released from sea salt (for example, bromine and chlorine ions) (Schroeder et al. 1998, Lu et al. 2001). It remains a research question what fraction of this reactive mercury is converted to toxic methyl mercury through biogeochemical reactions and taken up by animals and plants.

Numerical models of atmospheric transport and deposition are essential tools for understanding of individual mercury process and their interaction with the atmospheric system, and for the interpretation of field measurement data. An atmospheric computer model is a computerized mathematical representation of dynamical, physical, chemical, and radiative processes in the atmosphere (Jacobson 1999). Modeling of atmospheric mercury has undergone rapid development during last decade and several large-scale models are in operation today (Petersen et al. 1998), e.g. global models: GRAHM (Dastoor and Larocque 2004), CTM (Seigneur et al. 2001), regional models: ADOM (Petersen et al. 1995, 2001), CMAQ (Bullock and Brehme 2002), TEAM (Pai et al. 1997), HMET (Bergan et al. 1999), SAQM (Xu et al. 2000), RELMAP (Bullock Jr. 1997). However, these models were designed for application in a specific geographic region with no mercury depletion events and for a short period of time (days-week). During MDEs, gaseous elemental mercury (GEM) is converted to reactive gaseous mercury (RGM) (Lindberg et al. 2001) and total particulate mercury (TPM) (Lu et al. 
2001) that deposits quickly onto the ground. It is believed that oxidation of gaseous elemental mercury to reactive gaseous mercury occurs in the presence of reactive chemicals released from sea-salt aerosols. Therefore, an efficient aerosol module is needed to understand the gas-particle partitioning of mercury during mercury depletion events (MDE).

The objectives of this study are:

1. To incorporate mercury chemistry into a one-dimensional local scale air quality model fully coupled with vertical diffusion, dry deposition processes and cloud processes to simulate the transformation and deposition of atmospheric mercury. The developed model will be validated with observations.

2. To quantify the depletion of gaseous elemental mercury (GEM) over part of the Canadian arctic using the newly developed model. 


\section{Chapter 2}

\section{Literature Review}

\subsection{Introduction}

Mercury is a naturally occurring element, which has always been present in the environment (Munthe 1993). More than 25 mercury-containing minerals are known to occur in the earth's mantle, yet the average crystal abundance of this element is only about $0.5 \mathrm{ppm}$. Its principal ore is the mineral cinnabar $(\mathrm{HgS})$, which has been known and used by humankind for more than 2300 years (Schroeder et al. 1998). Elemental $\mathrm{Hg}$ is produced by heating mercury ores (Cinnabar) to liberate $\mathrm{Hg}^{0}$ vapor followed by condensing the vapor to liquid $\mathrm{Hg}^{0}$ (Lin and Pehkonen 1999). Mercury (Hg), atomic number 80 , is found among the transition elements of the periodic table, in-group IIB along with zinc and cadmium. Elemental $\mathrm{Hg}$ is silver-white liquid at standard temperature and pressure. As a result, metallic $\mathrm{Hg}$ has a substantial vapor pressure and exists in ambient air predominantly in the gaseous phase rather than in the particulate phase as is the case for other transition metals (Schroeder et al. 1991). Other unique and/or technologically important physio-chemical properties include: high surface tension $\left(\mathrm{Hg}^{\circ}\right.$ does not wet glass), high specific gravity $\left(13.55\right.$ at $\left.20^{\circ} \mathrm{C}\right)$, low electrical resistance, and a constant volume of expansion over the entire temperature range of its liquid state. Selected physical and chemical properties of some environmentally relevant mercury species are summarized in Table 2.1. 
Table 2.1 Physical/Chemical properties of mercury and some of its compounds (Schroeder et al. 1998)

\begin{tabular}{|c|c|c|c|c|c|c|}
\hline Property & $\mathrm{Hg}$ & $\mathrm{HgCl}_{2}$ & $\mathrm{HgO}$ & $\mathrm{HgS}$ & $\mathrm{CH}_{3} \mathrm{HgCl}$ & $\left(\mathrm{CH}_{3}\right)_{2} \mathrm{Hg}$ \\
\hline $\begin{array}{l}\text { Melting } \\
\text { Point }\left({ }^{\circ} \mathrm{C}\right)\end{array}$ & -39 & 277 & $\begin{array}{l}\text { Decomp. } \\
@+500\end{array}$ & $\begin{array}{c}584 \\
\text { (sublim.) }\end{array}$ & $\begin{array}{c}167 \\
\text { (sublim.) }\end{array}$ & - \\
\hline $\begin{array}{l}\text { Boiling } \\
\text { Point }\left({ }^{\circ} \mathrm{C}\right)\end{array}$ & $\begin{array}{c}357 \\
@ 1 \mathrm{~atm} .\end{array}$ & $\begin{array}{c}303 \\
@ 1 \mathrm{~atm} .\end{array}$ & - & - & - & $\begin{array}{c}96 \\
\text { (a) 1atm. }\end{array}$ \\
\hline $\begin{array}{l}\text { Vapour } \\
\text { Pressure } \\
(\mathrm{Pa})\end{array}$ & $\begin{array}{c}0.180 \\
\text { @ } 20^{\circ} \mathrm{C}\end{array}$ & $\begin{array}{c}8.99 \mathrm{E}-03 \\
\text { (a) } 20^{\circ} \mathrm{C}\end{array}$ & $\begin{array}{c}9.20 \mathrm{E}-12 \\
\text { @ } 25^{\circ} \mathrm{C}\end{array}$ & n.d. & $\begin{array}{c}1.76 \\
\text { (a) } 25^{\circ} \mathrm{C}\end{array}$ & $\begin{array}{l}8.3 \mathrm{E} 3 \\
@ 25^{\circ} \mathrm{C}\end{array}$ \\
\hline $\begin{array}{l}\text { Water } \\
\text { solubility } \\
(\mathrm{g} / \mathrm{l})\end{array}$ & $\begin{array}{l}49.4 \mathrm{E}-06 \\
\text { (a) } 20^{\circ} \mathrm{C}\end{array}$ & (a) $20^{\circ} \mathrm{C}$ & $\begin{array}{c}5.3 \mathrm{E}-02 \\
\text { (a) } 25^{\circ} \mathrm{C}\end{array}$ & $\begin{array}{l}\sim 2 \mathrm{E}-24 \\
\text { (a) } 25^{\circ} \mathrm{C}\end{array}$ & $\begin{array}{c}-5-6 \\
\text { (a) } 25^{\circ} \mathrm{C}\end{array}$ & $\begin{array}{c}2.95 \\
\text { (a) } 24^{\circ} \mathrm{C}\end{array}$ \\
\hline $\begin{array}{l}\text { Henry's } \\
\text { law } \\
\text { coefficient } \\
{\left[\mathrm{Pa} \mathrm{m}^{3}\right.} \\
\left.\mathrm{mol}^{-1}\right]\end{array}$ & $\begin{array}{c}729 \\
@ 20^{\circ} \mathrm{C} \\
0.32^{\mathrm{a}} \\
@ 25^{\circ} \mathrm{C}\end{array}$ & $\begin{array}{l}3.69 \mathrm{E}-05 \\
@ 20^{\circ} \mathrm{C}\end{array}$ & $\begin{array}{l}3.76 \mathrm{E}-11 \\
\text { @ } 25^{\circ} \mathrm{C}\end{array}$ & n.d. & $\begin{array}{c}1.6 \mathrm{E}-05 \\
@ 15^{\circ} \mathrm{C} \\
\text { and } \\
\mathrm{pH}=5.2\end{array}$ & $\begin{array}{c}646 \\
@ 25^{\circ} \mathrm{C} \\
0.31^{\mathrm{a}} \\
@ 25^{\circ} \mathrm{C}\end{array}$ \\
\hline & $\begin{array}{l}0.18^{\mathrm{a}} \\
@, 5^{\circ} \mathrm{C}\end{array}$ & & & & & $\begin{array}{l}0.15^{\mathrm{a}} \\
@ 0^{\circ} \mathrm{C}\end{array}$ \\
\hline
\end{tabular}

\footnotetext{
${ }^{\mathrm{a}}-$ Dimensionless units.
}

Because of its many useful properties, its economic importance in commerce, industry, mining, metallurgy, manufacturing, medicine and dentistry increased rapidly during the industrial revolution (Schroeder et al 1998). Mercury has a wide range of industrial applications, which consequently lead to natural air and water contamination. It is used to produce fungicides or pesticides in agriculture and was also added to paint. Various mercury compounds are also used as catalysts (e.g. for production of vinyl chloride 
monomer). Elemental mercury is used in chlor-alkali plants as a flowing cathode to produce sodium hydroxide and chlorine. Mercury is also a trace element in natural fuels such as coal and petroleum. Combustion of the fuels causes its direct emission into the atmosphere (Munthe 1993).

\subsection{Sources and Emissions}

The main sources of emissions of mercury to the atmosphere were characterized by the Expert Panel of Atmospheric Mercury Processes (1994) and defined as follows:

Anthropogenic mercury emissions refer to the mobilization and release of geologically bound mercury by man activities, with mass transfer of mercury to the atmosphere (Wilken 2001). Anthropogenic activities give rise to mercury mobilization and transfer of mercury to land, water and air include: Mining and smelting (e.g. zinc and copper smelting); burning of fossil fuels (coal and natural gas); industrial production processes (e.g. the mercury-cell chlor-alkali process for production of chlorine and caustic soda); agriculture (pesticides); consumption related discharges (including waste incineration) (Lindqvist and Rodhe 1985).

Natural mercury emissions refer to the mobilization and releases of geologically bound mercury by natural biotic and abiotic processes, with mass transfer of mercury to the atmosphere (Wilken 2001). Natural processes contribute to the flux of mercury and its compounds to the atmosphere: volcanic emissions, windblown dust from dry continental areas, emission of gaseous mercury from erosion and degassing or mineralized soils, vegetation and open ocean (Lindqvist and Rodhe 1985). 
Re-emission of mercury is the mass transfer of mercury to the atmosphere by biotic and abiotic processes from a pool of mercury that was deposited to earth's surface after initial mobilization by either anthropogenic or natural activities.

The two last pathways are considered as mercury emission from natural surfaces and they represent a large uncontrolled area of emissions sources. The total amount of mercury in the atmosphere is thus built from a mix of anthropogenic, natural and re-emission sources (Wilken 2001).

The majority of the current emissions from natural surfaces are the result of mercury deposited to the surfaces from industrial activities over the past century. Therefore, the emission from natural surfaces is sometimes defined as re-emission or re-entry (Stein et al. 1996).

About $50-75 \%$ of the annual mercury emissions are from anthropogenic sources (Fitzgerald, 1995). The profile of current anthropogenic emission sources in the U.S. are listed in Table 2.2

Table 2.2 Estimated $\mathrm{Hg}$ emissions from anthropogenic sources in the U.S. (Bullock Jr. et al., 1997)

Source

$\%$ of total anthropogenic emissions

Waste Incineration

Fuel combustion

Metal smelting

Chlor-alkali factories

Others
48

35

4

3

10 
As can be seen from Table 2.2, almost half of the emissions are from waste incineration because the feed materials contain relatively more $\mathrm{Hg}$ than fuel. Almost all $\mathrm{Hg}$ in combustion chambers is in the form of $\mathrm{Hg}(0)$ due to the high temperature of combustion. Chemical reactions with other flue gas constituents may occur when the temperatures of exhaust gases fall down, for example, formation of $\mathrm{HgCl}_{2}$. At stack conditions, some $\mathrm{Hg}(\mathrm{p})$ are also formed. Of the fossil fuels, $\mathrm{Hg}$ concentration in coal is much higher than in oil or in natural gas (Chu and Porcella, 1995).

On the global scale, $\mathrm{Hg}$ emissions from developed countries have remained constant since 1989, while in developing countries $\mathrm{Hg}$ emissions are still increasing. In Asia, Eastern Europe and the former USSR, more than $40 \% \mathrm{Hg}$ emissions are from coal combustion. In other regions, $28-40 \% \mathrm{Hg}$ emissions are from solid waste incineration (Pirrone et al. , 1996).

\subsection{Forms of Mercury in Atmosphere}

Mercury can exist in a large number of different physical and chemical forms with a wide range of properties, which is of fundamental importance for its environmental behavior. Conversion between these different forms provides the basis for mercury's complex distribution pattern, for local and global cycles, and for its biological enrichment and effects. The three most important chemical forms known to occur in the environment are: elemental mercury $\left(\mathrm{Hg}^{0}\right)$, which has a high vapor pressure and a relatively low solubility in water; divalent inorganic mercury $\left(\mathrm{Hg}^{2+}\right)$ which has a strong affinity for many inorganic and organic ligands, especially those containing sulfur; and methyl mercury $\left(\mathrm{CH}_{3} \mathrm{Hg}^{+}\right)$, which is resistant to environmental degradation, rapidly enriched by but only 
slowly destroyed by living organisms, and capable of passing through important biological barriers such as blood/brain barriers and the placenta (Lindqvist and Rodhe 1985). Under normal conditions, the atmospheric mercury is primarily elemental mercury (between 90 and 95\%), divalent mercury ( 3 to $4 \%$ ) and methylated mercury (2 to $3 \%$ ) (Wilken 2001).

Typical atmospheric concentrations of mercury species reported in the literature are presented in Table 2.3 (Seigneur et al. 1994).

Table 2.3 Typical Concentrations of Mercury species in the Atmospheric Environment

\begin{tabular}{llll}
\hline $\begin{array}{c}\text { Mercury } \\
\text { Species }\end{array}$ & $\begin{array}{c}\text { Typical gas-phase } \\
\text { concentration(ng/m3) }\end{array}$ & $\begin{array}{l}\text { Typical liquid-phase } \\
\text { concentration (ng/L) }\end{array}$ & Ref. \\
\hline $\mathrm{Hg}(0)$ & $2-5$ & $6-27 \times 10^{-3 \mathrm{a}}$ & Schroeder et al. 1991 \\
$\mathrm{Hg}(\mathrm{II})$ & $0.09-0.19$ & $3.5-13.3$ & Brosset 1987 \\
\hline & & & \\
\hline a - Estimated from gas-phase air concentrations by means of Henry's law.
\end{tabular}

\subsection{Atmospheric Transformations and Removal Processes}

The atmosphere is important in the environmental cycling of mercury, since it serves as a media for transport and transformation of mercury. This importance is mainly due to the large emissions of mercury to the air from point sources, but also to the fact that mercury can be (re-) emitted to the atmosphere from water surfaces and from soil and vegetation. This makes knowledge about the atmospheric turnover of mercury important for the assessment of various atmospheric mercury deposition scenarios and the subsequent 
environmental impact of the mercury load on terrestrial and aquatic ecosystems (Munthe 1993).

Atmospheric mercury can undergo various physical and chemical transformations before being deposited back to the ground. The speciation and chemical transformations of mercury in the atmosphere strongly influence its deposition mechanism and global cycling. The predominant form of mercury in air is $\mathrm{Hg}^{0}$, which is not very water-soluble. $\mathrm{Hg}^{0}$ has an atmospheric lifetime of $\sim 1-2$ years and can be transported over great distances. $\mathrm{Hg}^{0}$ is transported back to the earth mainly through dry deposition. The solubility of $\mathrm{Hg}(\mathrm{II})$ was found to be much higher than that of $\mathrm{Hg}(0)$ (Schroeder et al. 1991). Compared to $\mathrm{Hg}^{0}, \mathrm{Hg}(\mathrm{II})$ has a much shorter lifetime in the atmosphere (from several days to a few weeks). $\mathrm{Hg}(\mathrm{II})$ is a highly surface reactive species and deposits much faster than $\mathrm{Hg}^{0}$ through both dry and wet processes (Lin and Pehkonen 1999).

Different forms of mercury behave differently in air due to their different physical and chemical properties. Elemental mercury, $\mathrm{Hg}^{0}$ is a relatively stable long-lived species, while oxidized and methylated forms are rapidly removed from air by dry deposition or washout processes due to their high water solubility (Munthe 1993). Mercury is removed from the atmosphere through both wet and dry processes acting on $\mathrm{Hg}^{0}, \mathrm{Hg}(\mathrm{II})$ and $\mathrm{Hg}(\mathrm{p})$ species. It is not possible to select one of these processes as the most important since the actual deposition flux at a specific site will depend on the individual concentrations of the different mercury species which is highly variable for $\mathrm{Hg}(\mathrm{II})$ and $\mathrm{Hg}(\mathrm{p})$, the presence of other atmospheric constituents involved in removal processes (i.e. aerosols, ozone) and type of land use/cover/surface(Schroeder et al.1998) 
The oxidation of $\mathrm{Hg}^{0}$ to more water-soluble $\mathrm{Hg}$ (II) salts, followed by washout, rainout or condensation, remains the most probable pathway for the removal of mercury from air. Both gaseous and aqueous phase process may occur, but the predominance of $\mathrm{Hg}^{0}$ over other forms of mercury in air suggests that aqueous processes are more important. The secondary formation of particulate mercury in gas or aqueous phase, i.e. oxidation followed adsorption of mercury compounds on particles is also important. Lu et al. (2001) observed increase in TPM with decrease in GEM, suggested that GEM is converted to TPM. Reduction of dissolved $\mathrm{Hg}$ (II) compounds are also of interest since it provides a pathway for the removal of mercury from cloud and rainwater back to the air. Additionally, the condensation/evaporation cycle of water droplets in the atmosphere will also most certainly influence the chemical/physical form of mercury (Munthe 1993).

\subsection{Mercury Cycling in the Environment}

Mercury participates in a number of complex and interwoven environmental cycles that involve conversion between the different forms. Two of the most important of these cycles are the atmospheric cycle and the aquatic-biological cycle.

Fig 2.1 shows the atmospheric "emission-to-deposition cycle" of mercury. Mercury is released or re-emitted into the atmosphere by a number of natural and anthropogenic sources. After releasing into the atmosphere, mercury is subjected to a variety of physical, chemical and biological processes. The atmospheric cycle is derived from conversion in soil and water of divalent inorganic mercury, $\mathrm{Hg}(\mathrm{II})$, to gaseous elemental mercury $\left(\mathrm{Hg}^{0}\right)$ and/or $\left(\mathrm{CH}_{3}\right)_{2} \mathrm{Hg}$, and subsequent atmospheric re-oxidation of elemental mercury to water-soluble forms, which are then deposited. The processes transforming 
mercury among different forms influence the transport characteristics and deposition rate of this metal to the ground. Different mercury species have different transport characteristics. The atmospheric cycle entails retention in the atmosphere for long periods, and consequently, transport over very long distances. Mercury is removed from the atmosphere by both wet and dry deposition processes.

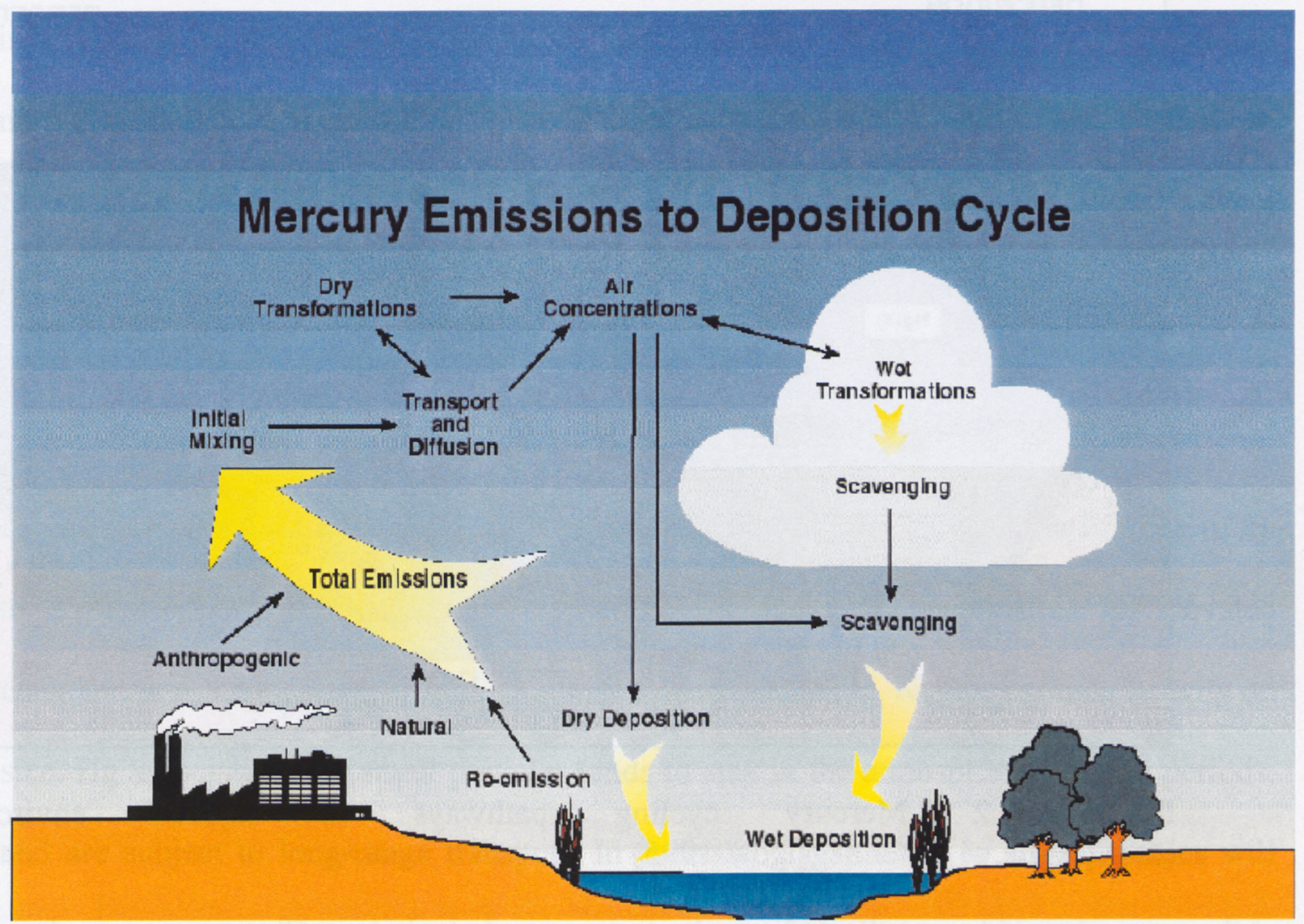

Figure 2.1 Atmospheric Mercury Cycle (http://www.frontiergeosciences.com/ 2002)

Wet deposition is an effective removal mechanism of atmospheric $\mathrm{Hg}$. Besides oxidizing elemental $\mathrm{Hg}$ to more soluble forms, precipitation also washes out particulate $\mathrm{Hg}$ and $\mathrm{Hg}$ (II). Precipitation can remove atmospheric $\mathrm{Hg}$ much more efficiently than dry 
deposition, but it is episodic in nature. On the other hand, dry deposition continuously cleans the atmosphere. The relative contributions of wet and dry deposition to the total depend on precipitation amount, surface wetness, size distribution of particles on which $\mathrm{Hg}$ attached to, and other meteorological and environmental conditions.

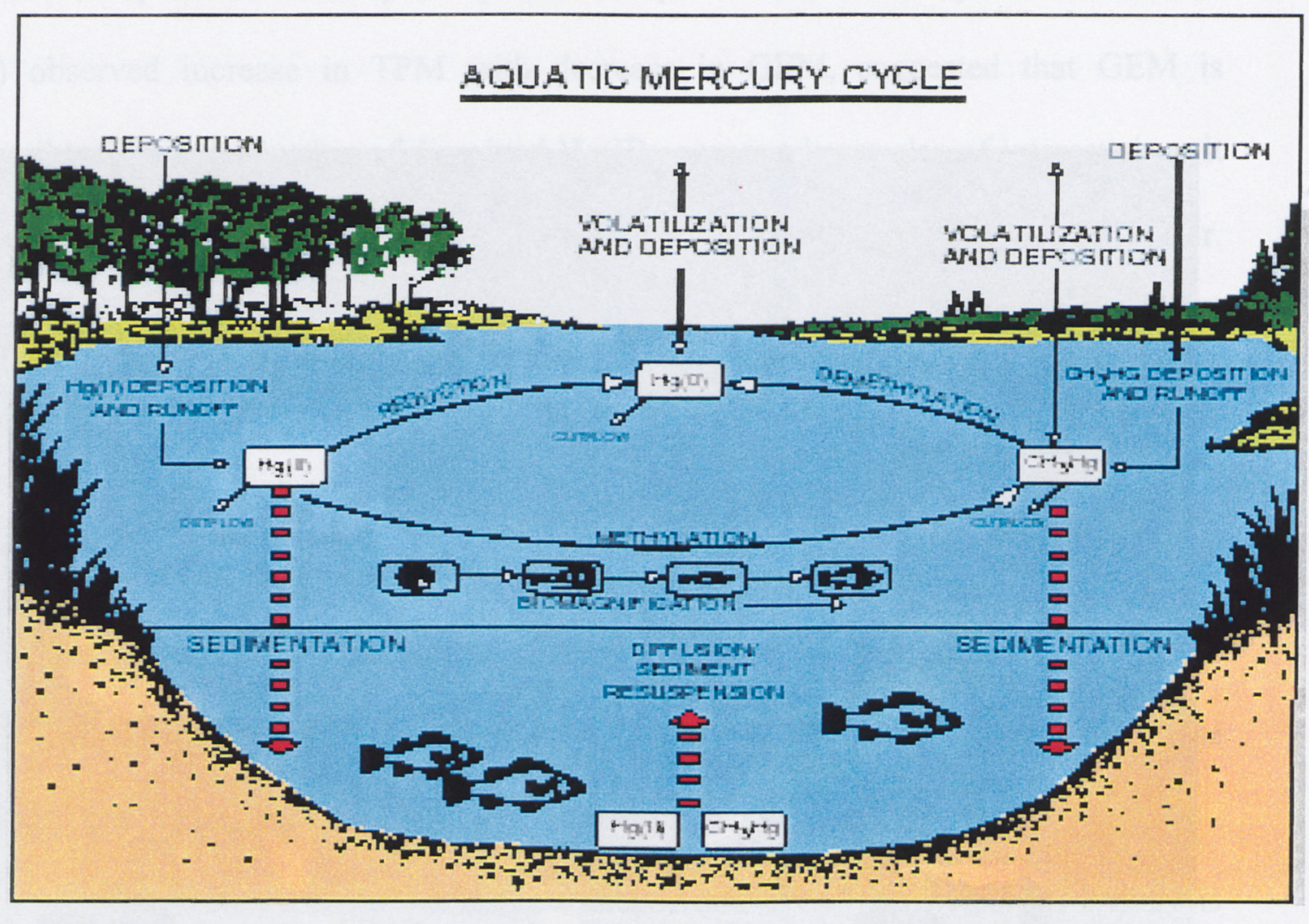

Figure 2.2 Mercury cycling pathways in aquatic environments (http://www.wi.water.usgs.gov/ 1995)

Fig. 2.2 shows a schematic drawing of mercury cycling in an aquatic ecosystem. The ultimate source of mercury to most aquatic ecosystem is deposition from the atmosphere, primarily associated with rainfall. As shown in Figure 2.2, atmospheric deposition contains the three forms of mercury: $\mathrm{Hg}^{0}, \mathrm{Hg}(\mathrm{II})$ and $\mathrm{CH}_{3} \mathrm{Hg}$, although the majority is $\mathrm{Hg}(\mathrm{II})$. Once in surface water, mercury enters a complex cycle in which one form can be 
converted to another, most important is the conversion to methyl mercury $\left(\mathrm{CH}_{3} \mathrm{Hg}\right)$, the most toxic form. Ultimately, mercury ends up in the sediments, fish and wildlife, or evades back to the atmosphere by volatilization (http://www.wi.water.usgs.gov/ 1995). Major features of the aquatic-biological cycle of mercury are the formation of methyl mercury, its enrichment in organisms and nutritional chains, and finally, destruction (demethylation) of methyl mercury. Although methyl mercury is the dominant form of mercury in higher organisms, it represents only a very small amount of the total mercury in an aquatic ecosystem and in the atmosphere. The rates of formation and destruction of methyl mercury are therefore of prime importance for the amount of mercury which can be enriched by aquatic organisms and thus for the concentration of mercury in these organisms (Lindqvist and Rodhe 1985).

\subsection{Local sources Vs. Long range transport}

Due to its low solubility and slow reaction rate, $\mathrm{Hg}(0)$ has an atmospheric lifetime of up to 2 years and can travel long distances (Lindberg 1987), responsible for elevated concentrations far from industrial sources. For particulate $\mathrm{Hg}$, its fate depends heavily on size. $\mathrm{Hg}$ associated with small particles tends to stay in the atmosphere for long periods, and are subject to long-range transport. In contrast, $\mathrm{Hg}$ attached to large particles will settle near sources. The relatively low concentrations of $\mathrm{Hg}$ (II) in ambient air suggest it is removed from the atmosphere quickly due to its high solubility. Table 2.4 presents measured $\mathrm{Hg}$ concentration levels in air (gaseous $\mathrm{Hg}$ ) and in rainwater at various locations. 
Table 2.4 Hg concentrations in air (vapor) and $\mathrm{Hg}$ in rain samples (Stein et al. 1996)

\begin{tabular}{llc}
\hline Location & In air(ng/m3) & In rain water(ng/l) \\
\hline Remote ocean & $1-3$ & $2-2.6$ \\
Rural & $3-10$ & $1.3-90$ \\
Urban & $2-30$ & $6-122$ \\
Large cities & $5-50$ & \\
Cinnabar deposits & $30-1600$ & \\
Chlor alkali waste ponds & $60-1000$ & \\
Power plant plume & $200-1700$ & \\
\hline
\end{tabular}

\subsection{Atmospheric Mercury Chemistry}

The chemistry of mercury in the atmospheric environment may take place in the gas phase and in the aqueous phase. Aqueous-phase chemistry is associated with particle and droplet chemistry. In addition, heterogeneous reactions may occur at the surface of atmospheric particles. Reactions that take place in the atmosphere will depend on the concentration of mercury or its compound as well as on the concentration of the species that react with mercury (Seigneur et al. 1994). As the chemical reaction of $\mathrm{Hg}$ in gas phase is several orders of magnitude slower than in the aqueous phase, studies of chemical reaction of $\mathrm{Hg}$ have concentrated on the aqueous-phase.

The chemistry of atmospheric mercury was first reviewed by Lindqvist and Rodhe (1985) (Lin and Pehkonen 1999). To date, the identified chemical transformation pathways of 
atmospheric mercury with measured kinetics include the gaseous phase oxidation of $\mathrm{Hg}^{\mathrm{o}}$ by ozone (P'yankov 1949; Slemer et al.1985; Hall 1995), aqueous phase oxidation of $\mathrm{Hg}^{\circ}$ by ozone (Iverfeldt and Lindqvist 1986; Munthe 1992), aqueous phase oxidation of $\mathrm{Hg}^{\mathrm{O}}$ by hydroxyl radicals (OH) (Lin and Pehkonen 1997), aqueous phase reduction of $\mathrm{Hg}$ (II) by S(IV) species (Munthe et al. 1991), aqueous phase photo reduction of mercuric hydroxide $\left(\mathrm{Hg}(\mathrm{OH})_{2}\right)$ (Xiao et al. 1994), aqueous phase reduction of $\mathrm{Hg}(\mathrm{II})$ by hydroperoxyl radicals $\left(\mathrm{HO}_{2}\right)$ (Pehkonen and Lin 1998), aqueous phase oxidation of $\mathrm{Hg}^{\mathrm{o}}$ by chlorine $(\mathrm{HOCl} / \mathrm{OCl}-)$, gaseous phase oxidation of $\mathrm{Hg}^{0}$ by nitrate radical $\left(\mathrm{NO}_{3}\right)$, and gaseous phase oxidation of $\mathrm{Hg}^{0}$ by chlorine $\left(\mathrm{Cl}_{2}\right)$ (Lin and Pehkonen 1998). In a recent study, Lin and Pehkonen (1998) pointed out that more oxidation pathways must be identified in order to better describe the chemistry of atmospheric mercury.

\subsection{Mercury and Human Health}

Mercury is considered an environmental contaminant due to its volatility, long atmospheric lifetime, and strong tendency to bioaccumulate. Bioaccumulation is the process by which organisms (including humans) can take up contaminants more rapidly than their bodies can eliminate them, thus the amount of mercury in their body accumulates over time. In North America, the 1990 U.S. Clean Air Act Amendments have identified mercury as one of the trace substances listed in the legislation as "hazardous air pollutants" because of its potentially significant effects on ecosystems and human health. Methyl mercury accumulated in the food chain, particularly in fish, is a potential human health hazard. As shown in Fig 2.2, methyl mercury is primarily produced in aqueous ecosystems from other mercury species. A very small amount of 
Methyl mercury is also found in the atmosphere and included in atmospheric deposition (Rudd 1995). Since 1950, a number of mercury poisoning caused by point sources have occurred (Schroeder and Jackson 1987). Mercury concentrations exceeding acceptable levels (usually $0.5-1 \mathrm{mg} \mathrm{Hg}$ per wet weight) have been found in fish in numerous rivers, lakes, and wetland, even far away from point sources (Pirrone et al. 1995). It is generally believed that atmospheric deposition of mercury, although rarely in the form of $\mathrm{MeHg}$, is the major source of mercury contamination in fish (Fitzgerald et al. 1998).

Humans generally uptake mercury in two ways : (1) as methyl mercury from fish consumption or (2) by breathing vaporous mercury $(\mathrm{HgO})$ emitted from various sources such as metallic mercury, dental amalgams, and ambient air. Consumption of produce and fish that have high concentrations of mercury may lead to adverse health effects in human body. Methyl mercury, which is a highly toxic organic form affects the central nervous system, impairs hearing, speech, vision and gait, causes involuntary muscle movements, corrodes skin and mucous membranes, causes chewing and swallowing to become difficult and in severe cases irreversibly damages areas of the brain.

\subsection{Modeling of the transport and transformation of atmospheric $\mathrm{Hg}$}

Numerical models of atmospheric transport and deposition are essential tools for the interpretation of field measurement data and as guidelines for the establishment of abatement strategies and measures for pollution control. Modeling of atmospheric mercury has undergone rapid development during the last decade and a number of largescale models are in operation today (Petersen et al. 1998, Ryaboshapko et al. 2002). Several numerical models of the atmospheric mercury cycle have been developed and 
applied on regional, as well as global scales. Dastoor et al. (2004) developed an on-line global/regional atmospheric heavy metals model(GRAHM) to understand the role of meteorology in mercury cycling. The GRAHM is based on Canada's operational Global Environmental Multiscale model at Canadian Meteorological Centre, which is an integrated forecasting, and data assimilation system. Lamborg et al. (2002) developed global scale model of mercury biogeochemistry to test understanding of the cycle and quantify past and present impact of human activity on the cycle. Model simulations of the atmospheric fate and transport of $\mathrm{Hg}$ suggest that in source areas the speciation of the $\mathrm{Hg}$ emissions governs the $\mathrm{Hg}$ deposition patterns but that in remote areas the atmospheric chemistry of $\mathrm{Hg}$ drives those deposition patterns (Pai et al. 1999).

Two basic types of models have been developed to date; where in the turbulent transport of mercury species is analyzed through either a Lagrangian or Eulerian approach (Petersen et al. 1998). In Lagrangian approach, air parcel moves with the local wind so that there is no mass exchange that is allowed to enter the air parcel and its surroundings (except of species emissions). The air parcel moves continuously, so the model simulates species concentrations at different locations at different time. In Eulerian approach, model simulates the species concentrations in an array of fixed computational cells. In recent years, researchers have compared five different mercury chemistry models using a common set of realistic atmospheric conditions. The main idea of this work was to demonstrate differences in the general behavior of $\mathrm{Hg}$ chemistry models in order to get a general sense of the magnitude of uncertainty inherent to current models (Ryaboshapko et al. 2002). 
The performance of the current models of atmospheric $\mathrm{Hg}$ is limited by several shortcomings. Due to lack of reliable data, $\mathrm{Hg}(0)$ emissions from natural surfaces were either included as background concentrations (Petersen et al., 1995; Bullock Jr. et al., 1997; Pai et al., 1997) or varied only with latitude and season (Shannon and Voldner, 1995). Further advancement of $\mathrm{Hg}$ modeling is in many aspects limited by a lack of quantitative knowledge of the atmospheric behavior of mercury. Many of the key processes involved in the transformation and deposition of atmospheric mercury remain unidentified or unquantified (Schroeder et al. 1998). The small number of global models can to a large extent be explained by the uncertainties related to emissions and transformations. The lack of worldwide and long-term observations is also a problem, which makes the testing of such models difficult (Bergan and Rodhe 2001). Current models need more sensitivity analysis to address the uncertainties and to simplify the model. In addition, detailed emission data and boundary concentrations have to be provided. Information provided by a sensitivity analysis may lead to simplification of the chemistry module.

\subsection{Mercury Measurements in the arctic}

Prior to 1992, no data existed on total gaseous mercury (TGM) levels in ambient air in the Canadian Arctic. An exploratory series of ground-based TGM measurements, using manual sampling and analysis procedures, was conducted at Alert, on the northern tip of Ellesmere Island, from August 1992 to August 1993. This historic data set provided the first annual time series of atmospheric $\mathrm{Hg}$ vapor concentrations anywhere in the Canadian Arctic. Then, in January 1995, high temporal-resolution monitoring was 
initiated at Alert with an automated $\mathrm{Hg}$ vapor analyzer. In 1996, The Canadian Atmospheric Mercury Measurement Network (CAMNet) was established with the goal of providing accurate, long-term measurements of TGM concentrations across Canada. These measurements are being used to investigate processes governing atmospheric concentrations of mercury, temporal and spatial variability of atmospheric mercury, and sources and sinks of atmospheric mercury. CAMNet currently consists of 11 monitoring sites across Canada to represent major geographical and ecological regions of Canada.

\subsection{Arctic Mercury Depletion}

Schroeder et al. (Schroeder et al. 1998) first observed the rapid decrease in background $\mathrm{Hg}$ concentration at Alert, where decreases in $\mathrm{Hg}^{0}$ were accompanied by increases in oxidized mercury species (Lu et al. 2001). Mercury depletion events are caused by specific chemical and physical conditions observed in the arctic during spring. Mercury depletion events occurs typically in the arctic from March to June, when the marine arctic ecosystems are also extremely active due to the increasing solar flux combined with the melting of sea ice (Schroeder et al. 1998). The implementation of high time resolution measurements of gaseous elemental mercury (GEM) at Canadian arctic site has revealed that $\mathrm{Hg}$ undergoes depletion episodes closely following changes in tropospheric ozone depletion events (Schroeder et al. 1998). However, as opposed to ozone, $\mathrm{Hg}$ is not destroyed, but the speciation is somehow altered to species with shorter atmospheric lifetime. In the arctic, during spring, the lifetime of GEM is significantly shorter, and GEM is depleted in less than 1 day during mercury depletion episodes (Schroeder et al. 1998, Lindberg et al. 2002, Bergan and Rodhe 2001). During MDEs, GEM is converted to oxidized mercury in the gas phase, the so-called reactive gaseous mercury (RGM) 
(Lindberg et al. 2001) and total particulate mercury (TPM) (Lu et al. 2001) that deposits quickly onto the ground. Researchers hypothesized that RGM is formed through a rapid, in-situ oxidation of $\mathrm{Hg}^{0}$ in the gaseous phase during MDEs. Production of RGM may be attributed to the same photo-chemically active halogen species involved in the surface ozone destruction, suggesting that the overall process is heterogeneous. Solar radiation and surface temperature of marine ice control the processes driving the conversion of GEM to RGM. Several hypotheses have been proposed where $\mathrm{Cl}$ and/or $\mathrm{Br}$ atoms or $\mathrm{ClO}$ and/or $\mathrm{BrO}$ are common candidates initiated by the heterogeneous reaction between ozone and sea salt chloride or bromide on the surface of sea ice. In the reaction mechanism, bromine and chlorine radicals are produced auto catalytically from a heterogeneous photochemical mechanism involving sea-salt aerosol. The halogen radicals $(\mathrm{Br} / \mathrm{Cl})$ and halogen oxide radicals $(\mathrm{BrO}, \mathrm{ClO})$ produced from the ozone destruction(Reaction 1) and serve as the primary oxidants that produce RGM (Lindberg et al. 2002).

$$
\begin{aligned}
& \mathrm{Br} / \mathrm{Cl}+\mathrm{O}_{3} \rightarrow \mathrm{ClO} / \mathrm{BrO}+\mathrm{O}_{2} \\
& \mathrm{BrO} / \mathrm{ClO}+\mathrm{Hg}^{0} \rightarrow \mathrm{HgO}+\mathrm{Br}^{*} / \mathrm{Cl}^{*}
\end{aligned}
$$

and/or

$$
\mathrm{Hg}^{0}+2 \mathrm{Br}^{*} / \mathrm{Cl}^{*} \rightarrow \mathrm{HgBr}_{2} / \mathrm{HgCl}_{2}
$$

The first speciation analysis of $\mathrm{Hg}$ carried out by $\mathrm{Lu}$ et al. (2001) during MDEs indicated that GEM is transformed to TPM by both uptake on particles and direct gaseous dry deposition to the local snow pack. RGM and TPM have elevated deposition rates compared to GEM, as evident from the high concentrations of $\mathrm{Hg}$ measured in snow samples from the Canadian High Arctic. 


\section{Chapter 3}

\section{Model Development}

\subsection{Introduction}

The purpose of this modeling study was to insert mercury chemistry module into a onedimensional (column model) climate model coupled with Canadian Aerosol Module (CAM) and to validate developed model by quantifying the depletion of GEM. The model was developed by starting with existing meteorological model (LCM-Local Climate Model) which is coupled with Canadian Aerosol Module (CAM) and then adding modules specific to Atmospheric mercury chemistry. This chapter describes the major theoretical consideration of the model development. The newly developed model was then applied to a portion of the Canadian arctic during springtime polar sunrise.

The model consists of three major components: (1) an active aerosol module (CAM), (2) a transport module for tracers (Atmospheric Transport) (LCM/FIZ-C) (3) Mercury Chemistry module

\subsection{Model Development}

\subsubsection{Canadian Aerosol Module (CAM)}

The Canadian Aerosol Module (CAM) was developed by Gong et al. (2003) to assess the influence of aerosols on climate. The Canadian Aerosol Module (CAM) developed for treating size-segregated aerosols in both air quality and climate models simulates the mass and number distributions of five major aerosols: sea-salt, sulphate, soil dust, black carbon and organic carbon. During MDEs, gaseous elemental mercury(GEM) is converted to reactive gaseous mercury(RGM) (Lindberg et al. 2001) and total particulate 
mercury(TPM) (Lu et al. 2001) that deposits quickly onto the ground. It is believed that oxidation of gaseous elemental mercury to reactive gaseous mercury occurs in the presence of reactive chemicals released from sea-salt aerosols. By using the sea-salt aerosol of CAM with arctic mercury chemistry, model can simulate the gas-particle partitioning of mercury during mercury depletion events. CAM is developed for the Canadian Climate Model with interactive aerosol components. It includes major aerosol processes in the atmosphere: generation, hygroscopic growth, coagulation, nucleation, condensation, dry deposition/sedimentation, below-cloud scavenging, aerosol activation, a cloud module with explicit microphysical processes to treat aerosol-cloud interactions and chemical transformation in clear air and in clouds. CAM is implemented in LCM with added mass conservation equations for size distributed aerosols and adapted to physics modules. Fig. 3.1 shows the block diagram of CAM models.

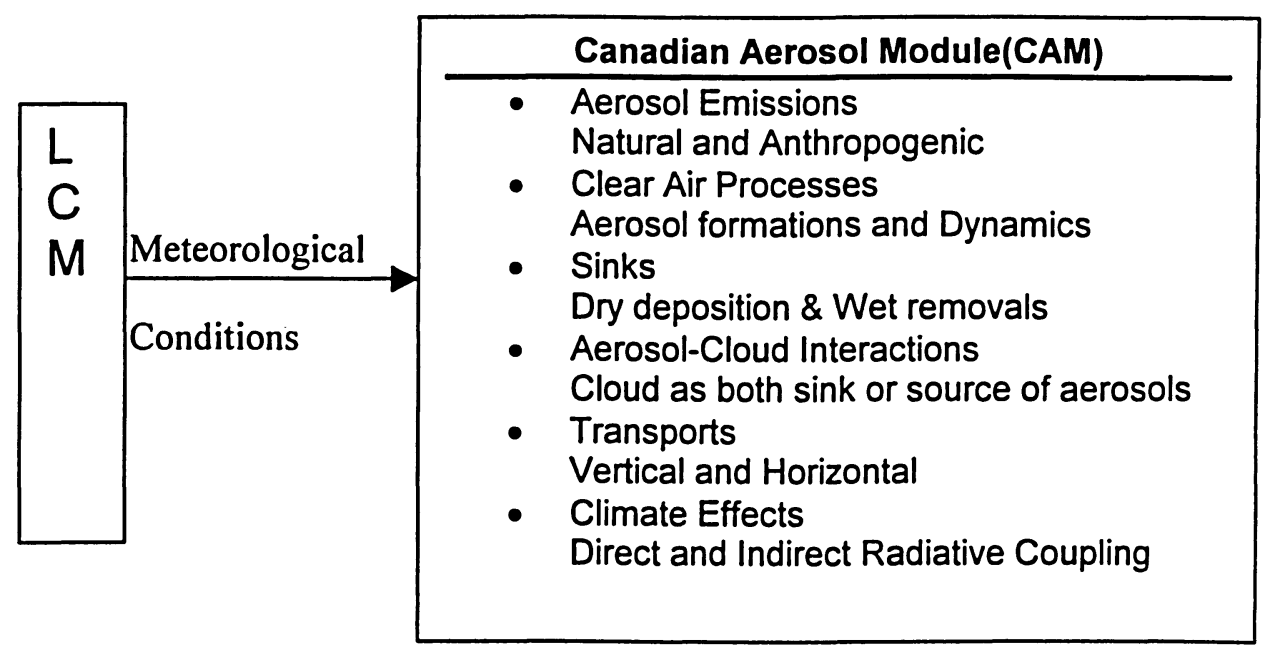

Figure 3.1 CAM general structure 
CAM uses LCM/FIZ-C to provide meteorological parameters to drive it. These include wind velocity, temperature, pressure, relative humidity and land surface information. It interfaces the meteorological driver with modules of parameterized aerosol processes in the atmosphere: (1) Emissions (Sources) (2) Clear Air Processes (3) Removal Processes (4) Aerosol-cloud Processes.

The aerosols in the CAM are represented by a discrete number of size bins $\left(N_{B}\right)$. Each bin may contain a specified number of aerosol types e.g. sea-salt and sulphate and interactions are allowed between bins depending on the physical/chemical processes involved. For each bin, a generalized prognostic mass balance equation for any aerosol type in a discrete size range $(i)$ can be written as

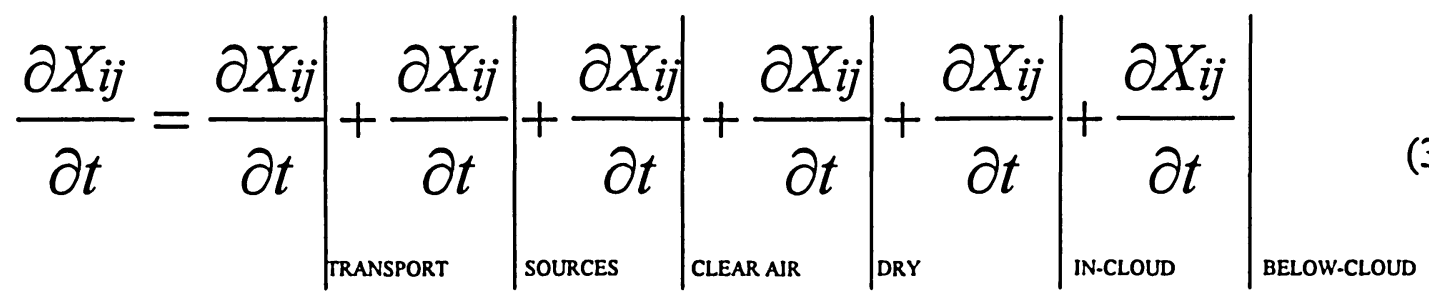

Where $\mathrm{Xij}$ is the concentration expressed as the mass-mixing ratio for the $\mathrm{i}^{\text {th }}$ size range of type $\mathrm{j}$ aerosols. In above equation, the aerosol concentration change has been divided into tendencies for transport, sources, clear air, dry deposition/sedimentation, in-cloud and below-cloud processes. The term tendency is defined as the concentration (mass mixing ratio) change rate due to an aerosol process. Since the process splitting method is used to solve equation (3.1), the tendency for each aerosol process is calculated separately. The Local Climate Model (LCM) to which CAM is coupled carries out the transport tendency, which includes the processes of advection and vertical diffusion/convection. The sources tendency includes surface emission rate of both natural and anthropogenic aerosols. Production of secondary aerosols, i.e. airborne aerosol mass-produced by 
chemical transformation of their precursors together with particle nucleation, condensation and coagulation form the clear-air processes. The aerosol processes form a set of ordinary differential equations and is solved by process-splitting technique.

\subsubsection{General Structure of LCM}

In order to use CAM, a general knowledge of climate model LCM is essential.

Local climate Model (LCM/FIZ-C) is a 1-D column model of the Canadian general circulation model (GCM) developed by Blanchet et al. (1996) to run on personal computers or servers. With its own dynamics, LCM does the physics only in a grid point (e.g. a column).

FIZ-C is a full physics climate and semi-prognostic model of the atmosphere. The Model requires initial conditions of the column and lateral transport from upstream region (dynamics tendencies) due to advection of prognostic variables of the GCM: wind velocity $(\mathrm{U}$ and $\mathrm{V})$, temperature $\mathrm{T}$, moisture $\mathrm{Q}$, and surface pressure (Ps). The first four variables are updated from mean rate of change with time $d U / d t, d V / d t, d T / d t$ and dQ/dt, which are partial derivatives due to dynamics(D) only. These tendencies are obtained from precalculated global simulation from GCMii climate reference runs. Since GCMii save only "physics" tendencies, the dynamics tendency is computed by the program "RESDYN" as a DYNamic RESidual of actual GCMii result and saved physics tendencies. Formally, the method may be described as follows: for any prognostic variables $\mathrm{F}$ from $(\mathrm{U}, \mathrm{V}, \mathrm{T}, \mathrm{Q})$ using the prototype equation.

$$
\mathrm{F}(\mathrm{n}+1)=\mathrm{F}(\mathrm{n})+\{\mathrm{D}(\mathrm{n})+\mathrm{P}(\mathrm{n})\}^{*} \mathrm{dt}=\mathrm{F}(\mathrm{n})+\mathrm{D}(\mathrm{n}) * \mathrm{dt}+\mathrm{P}(\mathrm{n}) * \mathrm{dt}
$$


The variable $F$ at time step $(n+1)$ is obtained from pervious time step $F(n)$ plus dynamics tendency $\mathrm{D}(\mathrm{n})$ from archived GCM giving the lateral advection of $\mathrm{F}$ in the column at time $\mathrm{n}$. For example, $\mathrm{dU}=(\mathrm{dU} / \mathrm{dt})^{*} \mathrm{dt}$ from dynamics plus its physics tendency $\mathrm{P}$ recalculate here from routine GCMii, the original GCMii's physics.

\subsubsection{Mercury Chemistry Module}

The mass transfer, chemistry and adsorption component of the model is illustrated in Fig. 3.2. It was implemented from Tropospheric Chemistry Module of Acid Deposition and Oxidant Model (ADOM) developed by Petersen et al. (Petersen et al. 1998). The mercury chemistry scheme was developed by systematic simplification of the detailed chemistry of atmospheric mercury process model, which is based on the current knowledge of physico-chemical forms and transformation reactions of atmospheric mercury species (Pleijel and Munthe, 1995). The model treats three gas-phase species $\left(\mathrm{Hg}^{0}, \mathrm{HgO}\right.$ and $\left.\mathrm{HgCl}_{2}\right)$, one particulate species $(\mathrm{Hg}(\mathrm{p}))$, six aqueous-phase $\mathrm{Hg}$ species $\left(\mathrm{Hg}^{0}, \mathrm{HgO}, \mathrm{HgCl}_{2}, \mathrm{Hg}^{2+}, \mathrm{Hg}\left(\mathrm{SO}_{3}\right)_{2}{ }^{2-}\right.$ and $\left.\mathrm{HgOHCl}\right)$, three $\mathrm{Hg}$ species adsorbed to soot particles present in the cloud droplets $\left(\mathrm{Hg}\left(\mathrm{SO}_{3}\right)_{2}{ }^{2-}, \mathrm{HgOHCl}\right.$ and $\left.\mathrm{HgCl}_{2}\right)$. It incorporates 21 reactions including mass transfer (R1-R5), aqueous phase (R6-R17) and gas phase (R20-R21) chemical reactions and adsorption processes on particles (R18-R19). The reaction rates are derived from published data and from assumptions of the rates of complex formation. For each process in the gas and aqueous phase, the stoichiometric reaction rate expressions have been transformed into first order expressions where the first order rate constants are functions of the reactant species. The rate constants used for model simulation are adopted from Petersen et al.(1998) and are provided in Appendix A. 


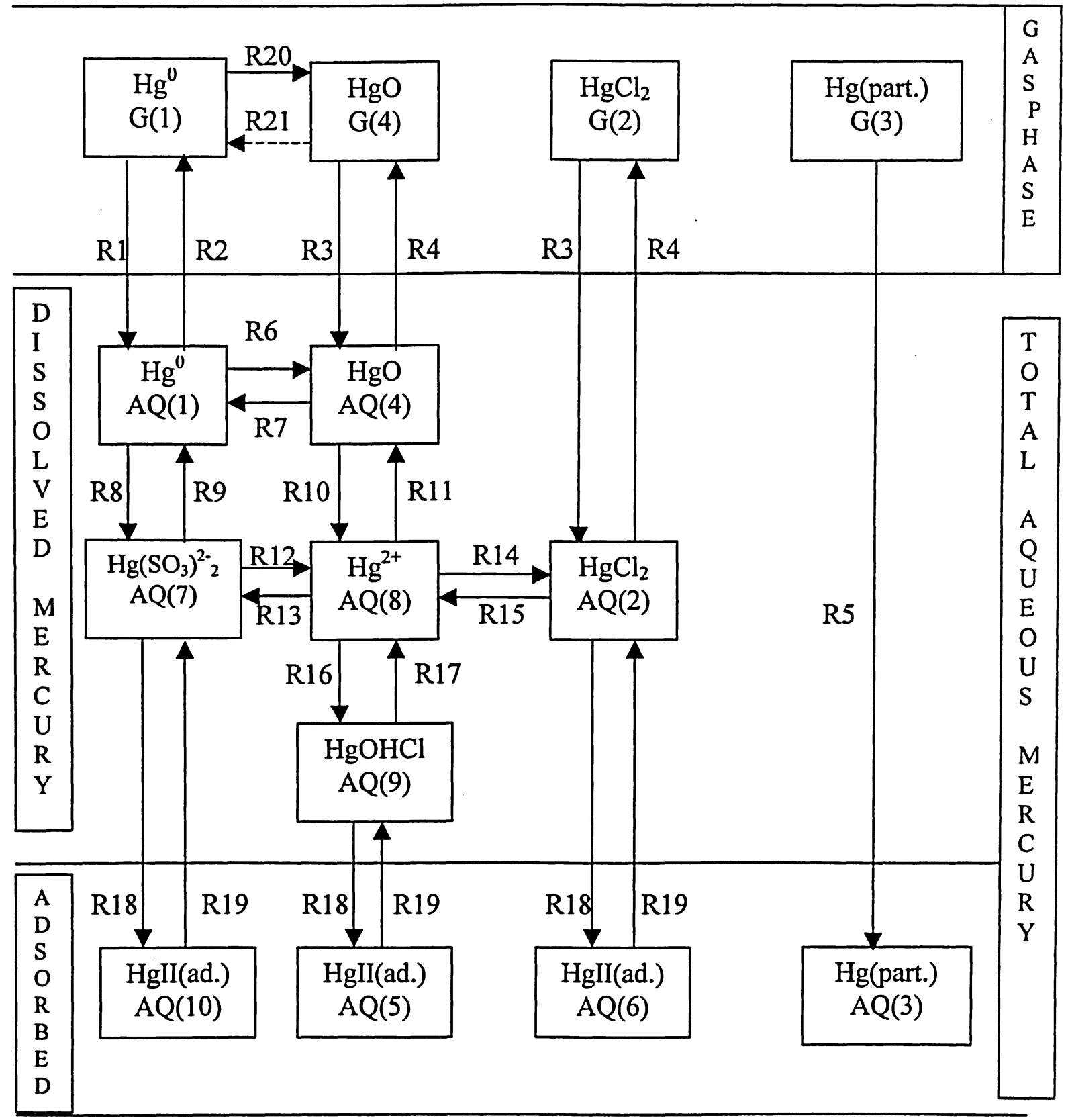

Figure 3.2 Mercury Chemistry Scheme used in 1-D Model 


\section{Scavenging}

Scavenging module includes the reversible mass transfer of gaseous elemental mercury $\left(\mathrm{Hg}^{0}\right)$ and oxidized gaseous mercury species $\left(\mathrm{HgO}\right.$ and $\left.\mathrm{HgCl}_{2}\right)$ to liquid cloud water, irreversible scavenging of these species by cloud ice and irreversible scavenging of particulate mercury $(\mathrm{Hg}($ part. $))$ by liquid cloud water and ice.

$$
\begin{aligned}
& {\left[\mathrm{Hg}^{0}\right] \text { gas } \Leftrightarrow\left[\mathrm{Hg}^{0}\right] \mathrm{aq} \text { (liquid cloud water) }} \\
& {[\mathrm{HgO}] \text { gas } \Leftrightarrow[\mathrm{HgO}] \mathrm{aq} \text { (liquid cloud water) }} \\
& {\left[\mathrm{HgCl}_{2}\right] \text { gas } \Leftrightarrow\left[\mathrm{HgCl}_{2}\right] \text { aq (liquid cloud water) }} \\
& {\left[\mathrm{HgO}_{\text {gas }} \Rightarrow[\mathrm{HgO}] \mathrm{aq}\right. \text { (cloud ice) }} \\
& {\left[\mathrm{HgCl}_{2}\right] \text { gas } \Rightarrow\left[\mathrm{HgCl}_{2}\right] \mathrm{aq} \text { (cloud ice) }} \\
& {[\mathrm{Hg} \text { (part.)]gas } \Rightarrow[\mathrm{Hg} \text { (part.)]aq (liquid cloud water, cloud ice) }}
\end{aligned}
$$

Reversible mass transfer processes of gaseous species (R1-R2, R3-R4) are treated as separate forward and backward reactions. The forward mass transfer rates are estimated from collision theory and sticking coefficients. The backward mass transfer rates are determined from the forward rates using Henry's law constant for $\mathrm{Hg}^{0}$ and $\mathrm{HgO} / \mathrm{HgCl}_{2}$ respectively. Particulate mercury is irreversibly scavenged by cloud water and cloud ice (R5).

\section{Gas Phase Chemistry}

In the gas phase, elemental mercury vapour $\left(\mathrm{Hg}^{0}\right)$ is the predominant form, constituting around $95 \%$ of the total mercury in air. Only one gas phase reaction of mercury is treated in the model; the oxidation of elemental mercury by ozone

$$
\mathrm{Hg}^{0}+\mathrm{O}_{3} \rightarrow \mathrm{HgO}+\mathrm{O}_{2} \quad \mathrm{k}_{20}=0.739 \times 10^{-9} \mathrm{ppb}^{-1} \mathrm{~s}^{-1} \text { (Hall 1995) }
$$


In the gas phase, this reaction is treated as a first order process with a constant ozone concentration so that $\mathrm{R}_{20}=\mathrm{k}_{20}\left[\mathrm{O}_{3}\right]$. In the gas phase, reduction of $\mathrm{Hg}(\mathrm{II})$ is not known so the rate constant for this process was given a very low value $\left(R_{21}=R_{20} / 1000\right)$ making it insignificant in the overall process.

\section{Aqueous-phase Chemistry}

Emissions of mercury are assumed to occur in the elemental form from model surface layer and emitted mercury will pass through the cloud water until an equilibrium concentration is established according to Henry's law. Elemental mercury, dissolved in the droplet, $\mathrm{Hg}(\mathrm{aq})$ will be oxidized by ozone to divalent mercury, $\mathrm{Hg}(\mathrm{II})$. The reaction is written as

$$
\mathrm{Hg}^{0}+\mathrm{O}_{3} \rightarrow \mathrm{HgO}+\mathrm{O}_{2} \quad \mathrm{k}_{6}=0.47 \times 10^{-8} \text { (Munthe 1992) }
$$

But is treated as a first order reaction in the model. The gas phase concentration and the Henry's law constant give the aqueous concentration of ozone. The product of aqueous phase oxidation $\mathrm{HgO}$ is not very likely to be long lived in the aqueous phase and reacts further to divalent mercury $\mathrm{Hg}^{2+}(\mathrm{aq})$.

$$
\begin{aligned}
\mathrm{HgO}(\mathrm{aq})+\mathrm{H}^{+} & \rightarrow \mathrm{Hg}^{2+}(\mathrm{aq})+\mathrm{OH}^{-}(\mathrm{aq}) \\
& \mathrm{k}_{10}=1 \mathrm{E}+10 \mathrm{M}^{-1} \mathrm{~S}^{-1} \text { (Pleijel and Munthe 1995) }
\end{aligned}
$$

In aqueous phase, divalent mercury $\mathrm{Hg}^{2+}$ forms a three separate complexes according to the chemical composition of the cloud water droplet; $\mathrm{HgCl}_{2}, \mathrm{Hg}\left(\mathrm{SO}_{3}\right)_{2}{ }^{2-}$ and $\mathrm{HgOHCl}$. Of the three major complexes nearly all the oxidized mercury exists in the chloride form. This is due to the relatively high chloride concentration found in the droplets (Pleijel and Munthe, 1995).

$\mathrm{Hg}^{2+}(\mathrm{aq})$ and sulphite ions $\mathrm{SO}_{3}{ }^{2-}$, form the complex $\mathrm{Hg}\left(\mathrm{SO}_{3}\right)_{2}{ }^{2-}$ via following reactions. 
$\mathrm{Hg}^{2+}(\mathrm{aq})+2 \mathrm{SO}_{3}{ }^{2-} \rightarrow \mathrm{Hg}\left(\mathrm{SO}_{3}\right)_{2}{ }^{2-}(\mathrm{aq}) \mathrm{k}_{13}=1 \mathrm{E}+15 \mathrm{M}^{-2} \mathrm{~S}^{-1}$ (Petersen et al. 1998)

$\mathrm{Hg}\left(\mathrm{SO}_{3}\right)_{2}{ }^{2-}$ is reduced back to $\mathrm{Hg}^{0}$ via following reaction.

$$
\begin{array}{ll}
\mathrm{Hg}\left(\mathrm{SO}_{3}\right)_{2}{ }^{2-} \leftarrow \rightarrow \mathrm{HgSO}_{3}+\mathrm{SO}_{3}^{2-} & \mathrm{k}_{9}=4.4 \mathrm{E}-04 \mathrm{~S}^{-1} \text { (Petersen et al. 1998) } \\
\mathrm{HgSO}_{3} \rightarrow \mathrm{Hg}^{0}+\text { Products } & \mathrm{k}=0.6 \mathrm{~S}^{-1} \text { (Munthe et al. 1991) }
\end{array}
$$

The dissociation of $\mathrm{Hg}\left(\mathrm{SO}_{3}\right)_{2}{ }^{2-}$ is the rate limiting step in the above two reactions and the rate constant of this reaction is used in the model.

The formation of $\mathrm{HgCl}_{2}$ is described as follows.

$$
\mathrm{Hg}^{2+}(\mathrm{aq})+2 \mathrm{Cl}^{-} \rightarrow \mathrm{HgCl}_{2} \text { (aq) } \quad \mathrm{k}_{14}=1 \mathrm{E}+15 \mathrm{M}^{-2} \mathrm{~S}^{-1} \text { (Petersen et al. 1998) }
$$

$\mathrm{Hg}^{2+}(\mathrm{aq})$ and the hydroxide ion, $\mathrm{OH}^{-}$, form $\mathrm{HgOH}^{+}$and $\mathrm{HgOHCl}$ as follows.

$$
\begin{aligned}
& \mathrm{Hg}^{2+}+\mathrm{OH}^{-} \rightarrow \mathrm{HgOH}^{+} \\
& \mathrm{HgOH}+\mathrm{Cl}^{-} \rightarrow \mathrm{HgOHCl} \quad \mathrm{k}_{16}=1 \mathrm{E}+15 \mathrm{M}^{-2} \mathrm{~S}^{-1} \text { (Petersen et al. 1998) }
\end{aligned}
$$

Particulate mercury is assumed to form as mercury complexes adsorb onto particles within the droplet. The parameterization of adsorption of dissolved mercury species on particles is based on an observed empirical equilibrium relation between mercury concentrations (Petersen et al. 1995) and the occurrence of soot particles in precipitation samples (Iverfeldt, 1991). The adsorption rate, typical time for diffusion in aqueous phase of $0.02 \mathrm{~S}^{-1}$ is used for the forward rate constant $\mathrm{R} 18$. The reverse desorption rate constant R19 depends on soot particle concentration and the soot particle radius.

\section{Mathematical description of the model}

In mathematical terms, the chemical part of the model consists of 24 differential equations, representing the reactions in the gas and aqueous phase for 14 mercury species 
in the boundary layer. For a species $i$, the differential equation that represents the concentration change in time, $C i(t)$, is expressed as

$$
\frac{d C i(t)}{d t}=P i-L i
$$

Where $P i$ is the chemical production rate, $L i$ is the chemical loss. Differential equations are solved using the Young and Boris predictor corrector scheme(Young and Boris, 1977).

\subsection{Model Implementation}

By incorporating mercury chemistry module into one-dimensional climate model (LCM/FIZ-C), the newly developed model was capable of simulating the atmospheric chemistry of mercury. The major modules making up the mercury version of onedimensional column model together with the model input data sets are schematically depicted in Fig.3.3.

The mercury wet scavenging module consisting of cloud physics and mercury gas and aqueous phase chemistry. Stratus (layer) cloud type is considered in wet scavenging module. The vertical diffusion module simulates the vertical distribution of mercury species in the column.

Dry deposition sub module of CAM is used to modeled the dry deposition of gaseous mercury and particulate mercury. Dry deposition is modeled in terms of a deposition velocity for gaseous mercury species, which is calculated as the inverse of the sum of the area weighted aerodynamic, surface and canopy resistances. 


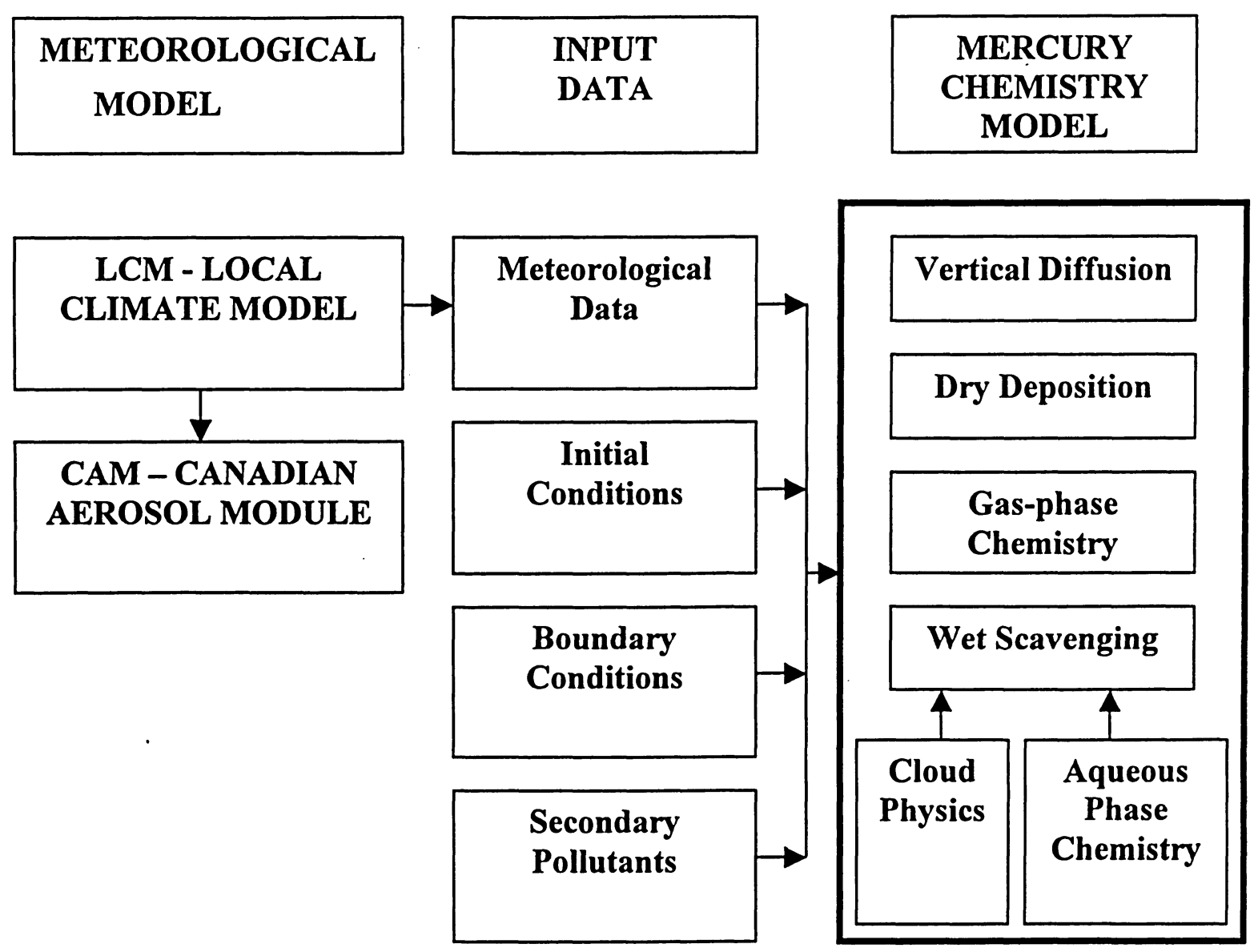

Figure 3.3 Column model for mercury.

$$
V_{d}=\frac{1}{R_{A}+R_{D}+R_{C}}
$$

The aerodynamic resistance $\left(\mathrm{R}_{\mathrm{A}}\right)$ is determined from meteorological input such as stability and applies to all species. The surface resistance $\left(R_{D}\right)$ is calculated from the land-use type and the physical and chemical properties of the species. The canopy resistance $\left(R_{C}\right)$ responds to the incoming solar radiation and meteorology. Dry deposition velocities of particles differ from those of gases in two ways. First, particles are heavier than gases; thus, particle sedimentation velocities must be included in their dry deposition equation. 
Second, because of their weight, particles tend to stay on surfaces once they deposit; thus, the surface resistance term is ignored in modeling the dry deposition of particulate mercury.

Dry deposition rates of elemental mercury are difficult to assess. The very low solubility of elemental mercury suggests that dry deposition will be a slow process. However, since the large majority of the observed air concentration is elemental mercury, even a small dry deposition rate could result in significant deposition. Gaseous divalent mercury dry deposition characteristics are assumed to be similar to that of nitric acid because of their similar solubility. Similarly, the dry deposition rates of sulfate particles are used for particulate-phase mercury. Dry deposition of particulate mercury is modeled using the average deposition velocity of sulfate particles. For sulfate particles, the deposition velocity is determined by dividing the particle size distribution into 12 size intervals, calculating the deposition velocity for each size interval.

Data required to drive the model are meteorological data, initial concentration of mercury species, and initial and final boundary conditions. For running the $\mathrm{Hg}$ chemistry module, observed ambient soot and ozone concentrations were provided to carry out the simulation. The primary simulation outputs included ambient concentrations of mercury species and dry deposition of reactive gaseous mercury and particulate mercury and wet deposition of aqueous mercury species at time step of $20 \mathrm{~min}$. 


\section{Chapter 4}

\section{Local Scale Transport, Transformation and Deposition of}

\section{Atmospheric Mercury : A Simulation Study}

\subsection{Introduction}

This chapter presents a simulation study on the transformation and deposition of atmospheric $\mathrm{Hg}$ in Alert, Canada using the column model developed and described in the previous chapters. The purpose of the study was to simulate the episodic depletions of gaseous elemental mercury(GEM) after spring time polar sunrise at Alert, Canada.

\subsection{Simulation procedure}

\subsubsection{Procedure}

Validation was conducted by comparing simulated concentrations of reactive gaseous mercury, particulate mercury and ratios of RGM/GEM, PM/GEM and PM/RGM with observations conduced by Meteorological Services of Canada. Reactive gaseous mercury (RGM) is the sum of concentration of all divalent mercury species in gas phase.

\subsubsection{Location of simulation}

The Local scale column model was simulated for the spring month of April 2002. The model was initialized at the beginning of month and after few time steps of mercury spinup in the atmosphere; the modeling results show a well-balanced atmosphere (with respect to mercury) at Alert, Canada. 
The simulation started at 12 a.m. Alert time on the $1^{\text {st }}$ day of April 2002. The location of the simulation covered Alert, Canadian Arctic as shown in Fig. 4.1.

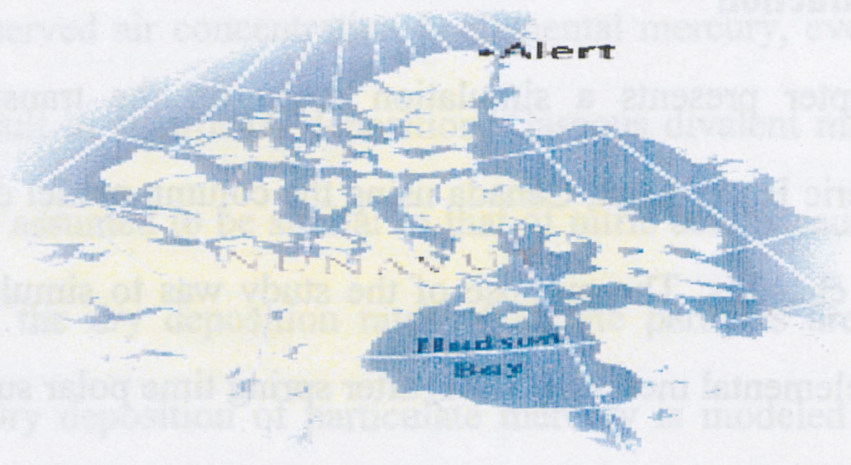

Figure 4.1 Location of Simulation

The Alert site is on the northern tip of Ellesmere Island, located at $82.5^{0} \mathrm{~N}, 62.5^{0} \mathrm{~W}$. There was only one grid point in horizontal direction. The vertical grid consists of 10 unequally spaced levels between the surface and the top of column at $13 \mathrm{~km}$. The center of the lowest layer was approximately $75 \mathrm{~m}$ above the ground. The top of the modeling domain was approximately $13 \mathrm{~km}$.

\subsubsection{Model Inputs}

The meteorological input data needed by model are wind velocity, temperature, surface pressure, relative humidity, mixing height, amount of cloud cover and amount of precipitation. A cloud fractional coverage is used to divide the grid cell into cloudy and clear section. The cloud parameters determine the volume of the aqueous-phase reactor for the chemistry calculations. 
Initial and Boundary conditions are needed for all species in the model. This includes the emitted compounds and secondary compounds affecting the atmospheric chemistry of mercury. Within the model surface layer, the model was initialized every time step with observed gaseous elemental mercury (GEM) concentration. Also observed concentrations of $0.008 \mathrm{ng} / \mathrm{m}^{3}$ and $0.222 \mathrm{ng} / \mathrm{m}^{3}$ were used as initial conditions for reactive gaseous mercury ( $\mathrm{RGM}, \mathrm{Hg}(\mathrm{II})$ ) and particulate mercury ( $\mathrm{PM}, \mathrm{Hg}(\mathrm{p})$ ) respectively. At the top boundary, it was assumed that there was no exchange.

The mercury chemistry requires the specifications of ozone and soot carbon concentration in ambient air. Since no data for air concentrations of soot (carbon) particles were available for this month, following Petersen et al. (1998) the constant concentration of soot was fixed at $1 \mathrm{ppb}$. Also, The concentration of ozone was fixed at $35 \mathrm{ppb}$.

\subsubsection{Sample collection and analysis}

All experiments were conducted by Meteorological services of Canada at Alert, Canada for the month of April 2002, as MDE is observed in the 3-month period following polar sunrise. The automated Tekran model $2537 \mathrm{~A} \mathrm{Hg}^{0}$ analyzer with the 1130 gaseous speciation denuder model and 1135 particulate $\mathrm{Hg}$ pyrolysis unit was used for continuous measurement of mercury compounds.

Fig. 4.2 shows a schematic of the flow path for the overall $1130 / 1135$ systems as integrated with $2537 \mathrm{~A}$. The principle of the Tekran $2537 \mathrm{~A}$ is as follows: a measured volume of sample air is drawn through a gold trap that quantitatively retains elemental mercury. The collected mercury is desorbed from the gold trap by heat and is transferred by argon into the detection chamber, where the amount of mercury is detected by cold 
vapor atomic fluorescence spectroscopy. The model 1130 speciation unit consists of a heated denuder module, a pump module and a controller module. The model 1130 controller module integrates the analytical capabilities of the Tekran model 2537A unit with the 1130 speciation module allowing for continuous measurement of both $\mathrm{Hg}^{0}$ and RGM. The 1130 speciation unit was configured to collect 2-h RGM samples onto a KClcoated quartz annular denuder. After the 2-h sampling period, the 1130 system was flushed with $\mathrm{Hg}$-free air and the annular denuder was heated to $600{ }^{\circ} \mathrm{C}$. The RGM

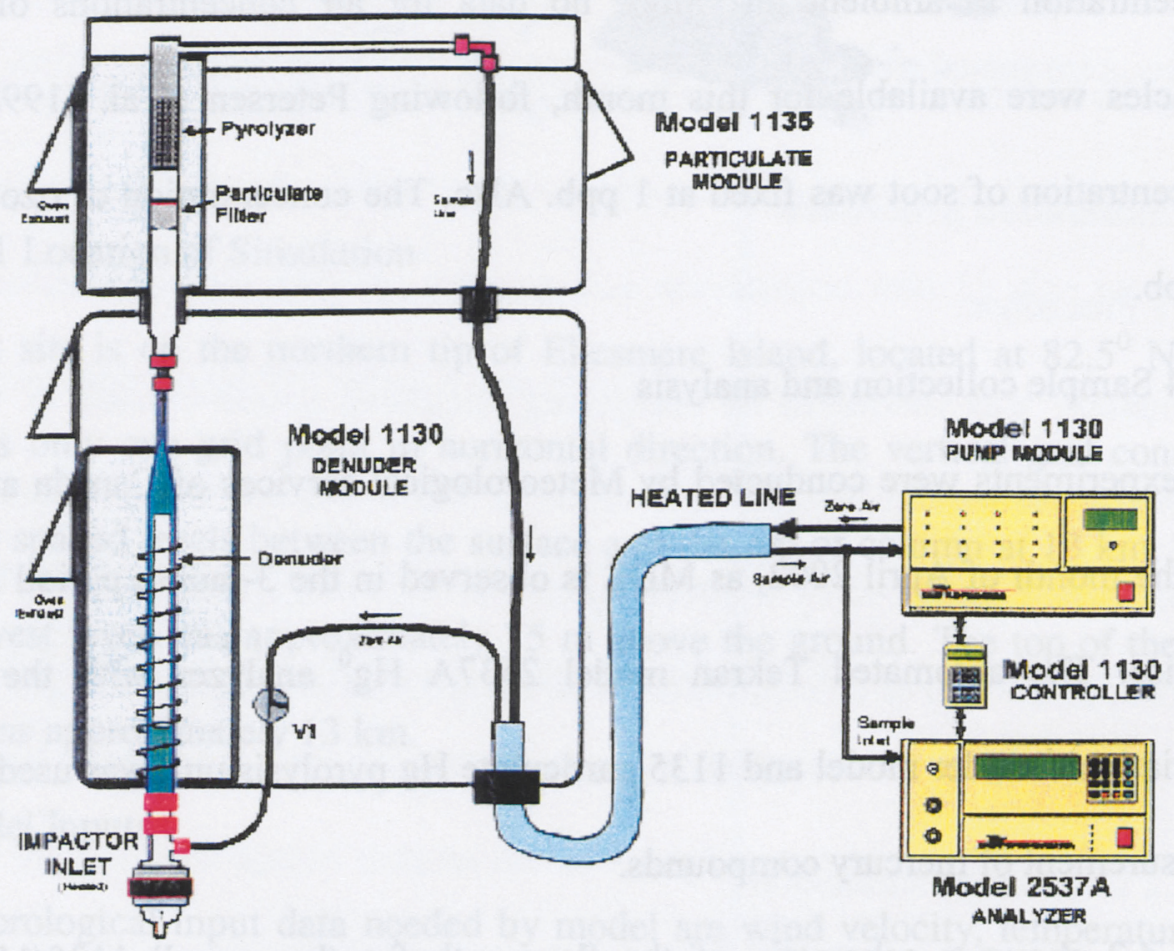

Figure 4.2 Automated Tekran 2537 $\mathrm{A} \mathrm{Hg}^{0}$ Analyzer with 1130/1135 speciation systems (Tekran Inc.)

collected on the denuder was thermally decomposed into a $\mathrm{Hg}$-free air-stream and subsequently analyzed as $\mathrm{Hg}^{0}$. The Tekran 1135 pyrolysis unit collects $\mathrm{Hg}$-p $(<2.5 \mu \mathrm{m}$ in diameter) onto a quartz filter after collecting RGM on quartz denuder. The 1135 system 
was flushed with Hg-free air and the pyrolyzer for the quartz filter was preheated to $800{ }^{\circ} \mathrm{C}$ to convert all Hg-p to elemental form and quantified by the Tekran 2537A.

Fig. 4.3 shows the measured concentration of GEM, RGM and PM for the month of April 2002 (Source: Alexandra Steffen, MSC, Downsview, Ontario). For observed data, Tekran unit was stopped for calibration on $10^{\text {th }}$ April, so there are no data for this day.

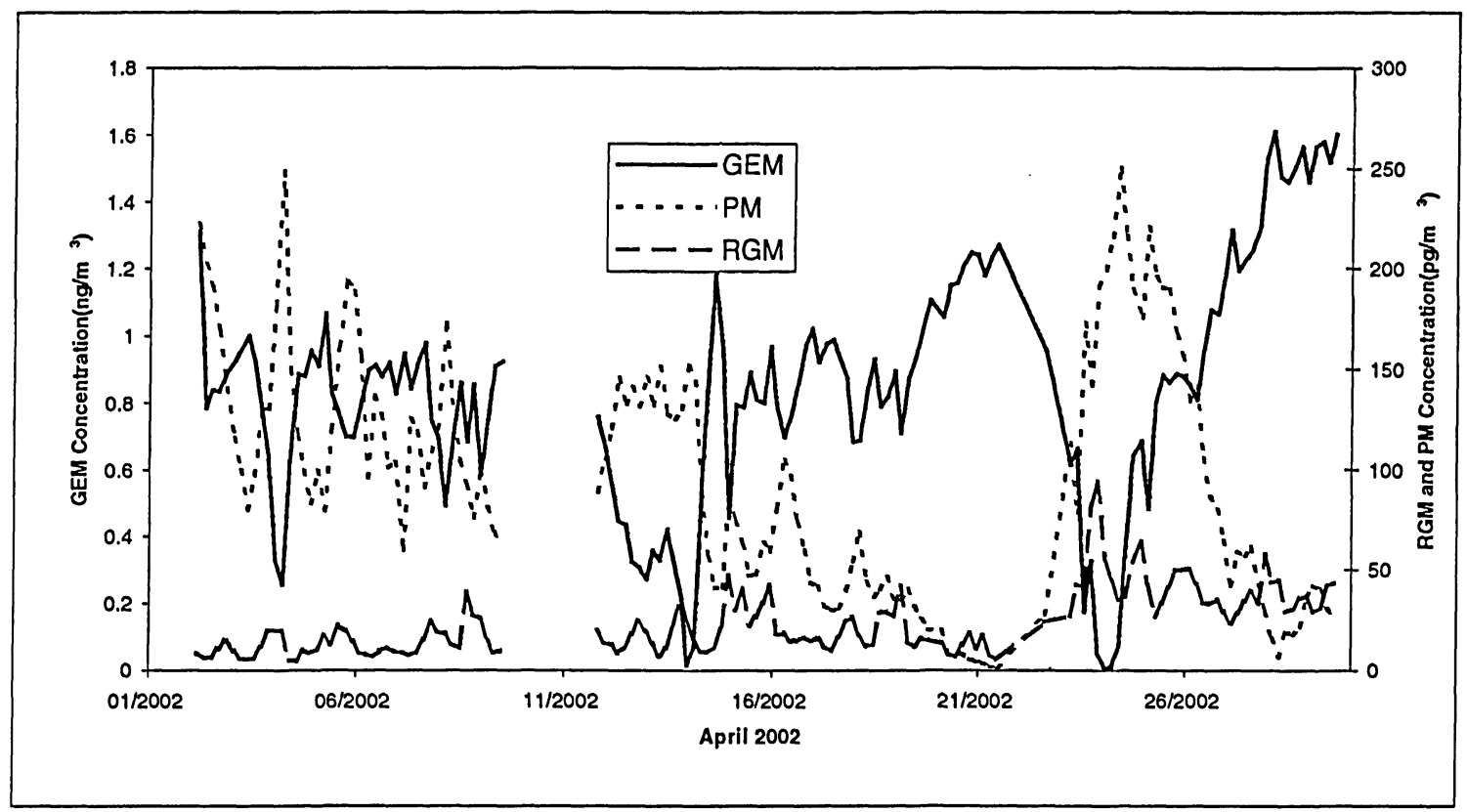

Figure 4.3 Observed Concentrations of GEM, RGM and PM (Source: Alexandra Steffen, MSC, Downsview, Ontario)

\subsubsection{Simulation outputs}

The model integrates complete atmospheric physical state and physio-chemical changes of mercury species in the column at the interval of $20 \mathrm{~min}$. time step. The major outputs of the simulation were ambient $\mathrm{Hg}$ concentrations, dry deposition and wet deposition values at surface grid. In model results presented here, RGM is the sum of concentration of all divalent mercury species in gas phase. 


\subsection{Simulation results}

The results of the model simulations are presented below.

\subsubsection{Ambient concentrations of mercury species}

Computed model concentrations of mercury species are compared with observations at Alert, Canada for April 2002.

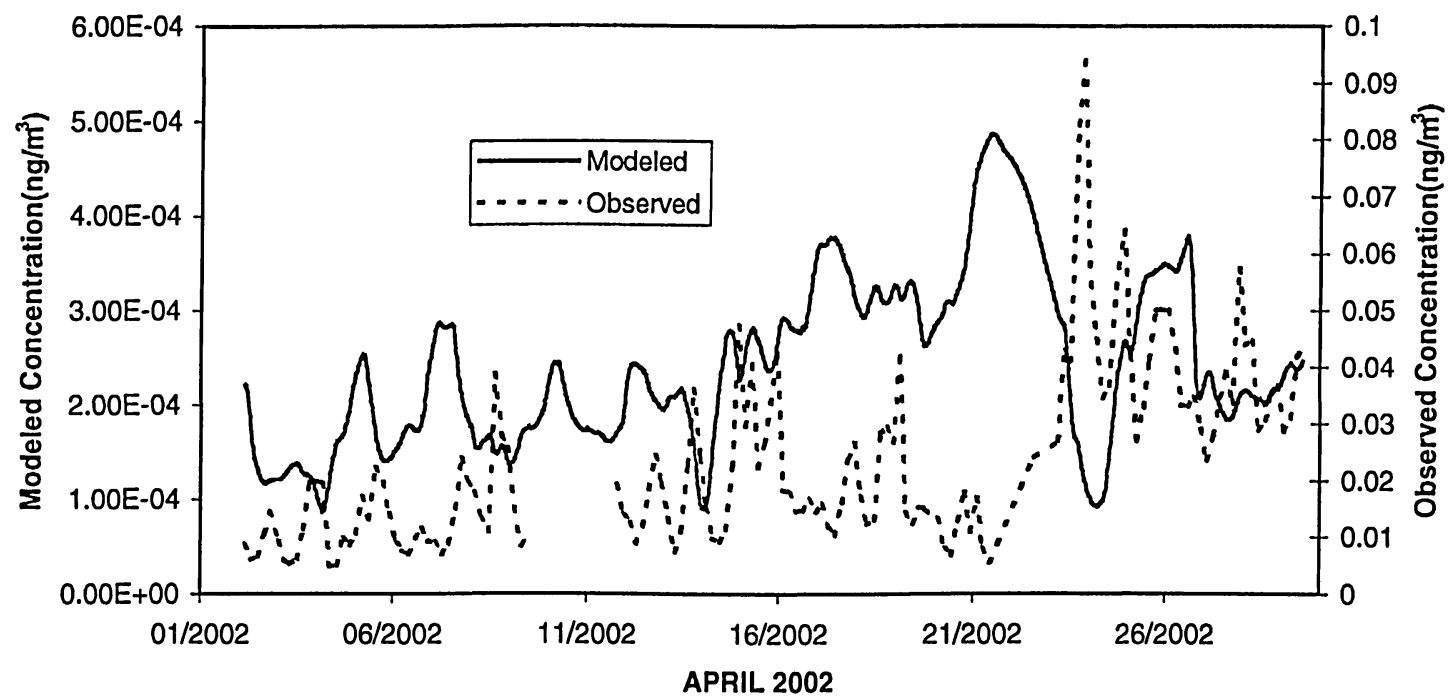

Figure 4.4 Simulated and Observed Reactive Gaseous Mercury Concentrations

Fig. 4.4 compares the modeled concentration of reactive gaseous mercury (RGM) with observed concentrations for spring month of April 2002. In the case of reactive gaseous mercury, average measured values for April 2002 at Alert was $23.49 \mathrm{pg} / \mathrm{m}^{3}$. Computed average concentration from the model was $0.256 \mathrm{pg} / \mathrm{m}^{3}$. The simulated concentration of reactive gaseous mercury (RGM) is very low compared to observed concentration. The reason for under predicted concentrations of reactive gaseous mercury by the model is that not enough gaseous elemental mercury (GEM) is converted to reactive gaseous mercury (RGM). Recent research on the mercury depletion event reveals that depletion is initiated by the presence of halogen molecules. In this model, there is only one gas phase 
reaction is considered. The possible reason for not enough conversion of gaseous elemental mercury to reactive gaseous mercury could be non-inclusion of halogen chemistry and other oxidants, which oxidizes gaseous elemental mercury to reactive gaseous mercury.

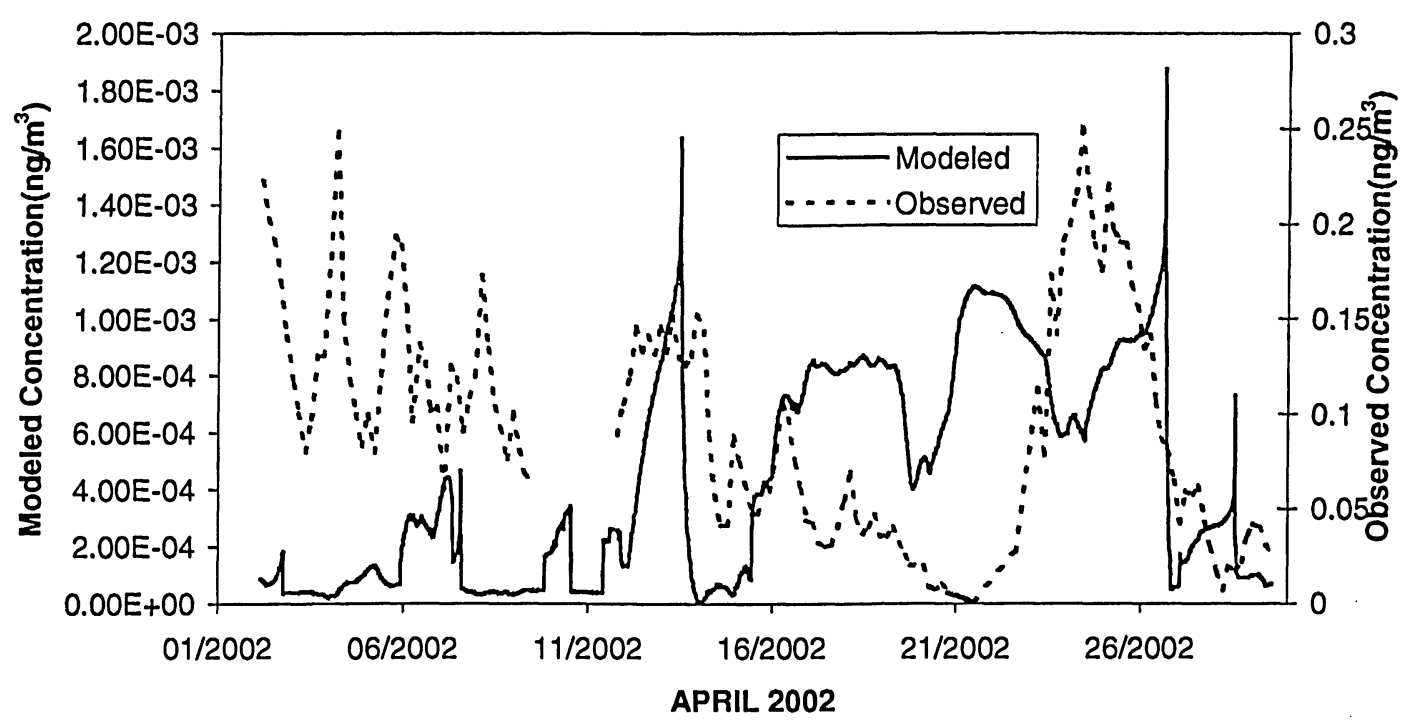

Figure 4.5 Simulated and Observed Particulate Mercury $(<2.5 \mu \mathrm{m}$ in dia.) concentrations Fig. 4.5 compares the modeled concentration of particulate mercury (PM) with observed concentrations for spring month of April 2002. In the case of particulate mercury, average measured values for April 2002 at Alert was $94.12 \mathrm{pg} / \mathrm{m}^{3}$. Computed average concentration from the model was $0.44 \mathrm{pg} / \mathrm{m}^{3}$. The simulated concentration of particulate mercury is very low compared to observed concentration. Particulate mercury is emitted from anthropogenic sources and also formed in the atmosphere via gas/solid interaction and/or evaporation of cloud droplets. In arctic, there is no anthropogenic source of mercury, so only gas-particle interaction could only be the mechanism for formation of particulate mercury in arctic environment. The formation of particulate mercury is governed by the physical adsorption equilibrium of $\mathrm{Hg}^{0}$ between gas and particle phases 
(Sakata and Marumoto 2002). For particulate mercury, reason could be there is no gasparticle partitioning of mercury treated in the model. Also, there is no source of particulate mercury, as there is no connection between particulate mercury and other gaseous species in the model.

The underestimation of both RGM and PM concentration could also be attributed to the lack of transport due to the 1-D feature of the model.

\subsubsection{Ratio of RGM/GEM, PM/GEM and PM/RGM}

Fig. 4.6 compares the modeled ratio of RGM/GEM with observed ratio for spring month of April 2002. The average observed ratio of RGM/GEM is $3.36 \mathrm{E}-02$, whereas the calculated RGM/GEM ratio is 3.62E-04. Fig. 4.6 reveals a striking similarity pattern of modeled ratio and observed ratio, but the magnitude of simulated ratio of RGM/GEM is low compared to observed ratio.

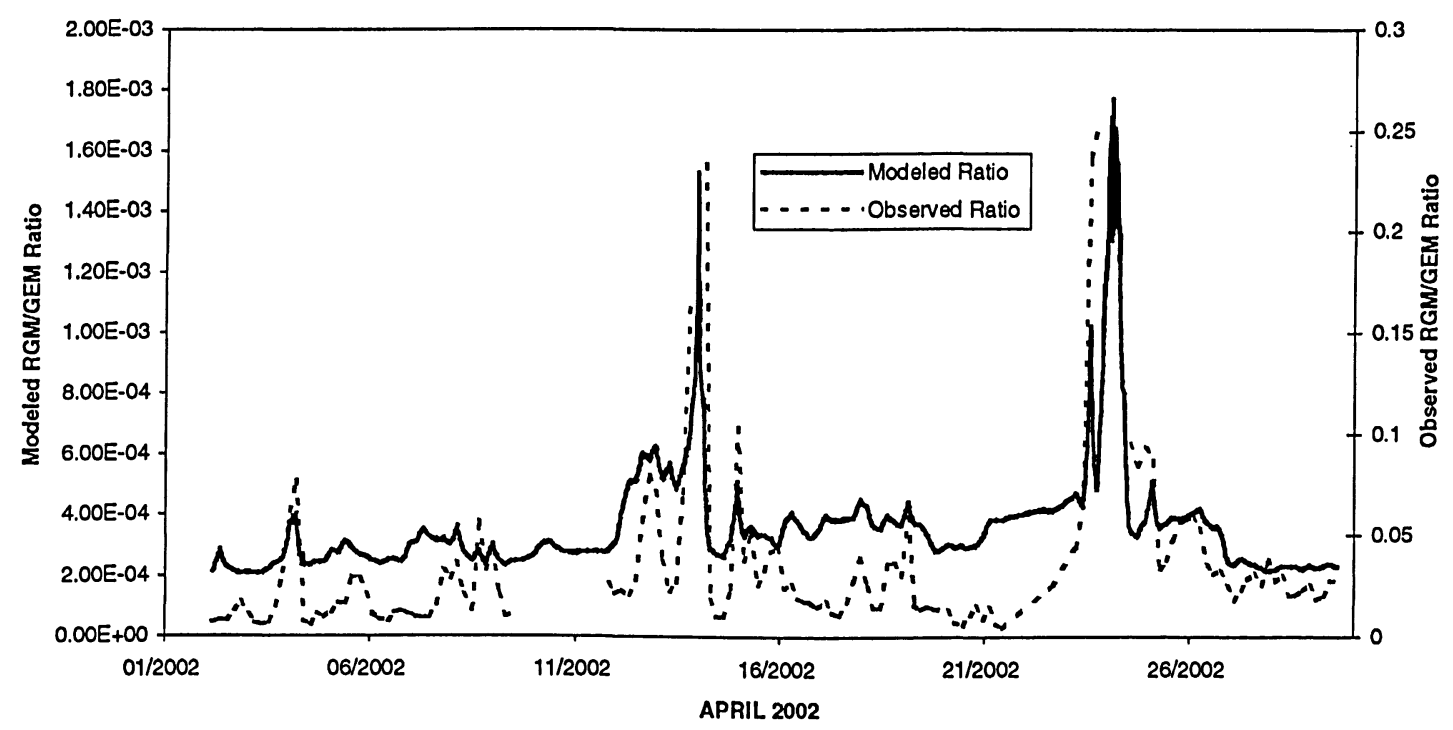

Figure 4.6 Simulated and Observed ratio of RGM/GEM 
Fig. 4.7 compares the modeled ratio of PM/GEM with observed ratio for spring month of April 2002. The average observed ratio of PM/GEM is 1.48E-01, whereas the calculated $\mathrm{PM} / \mathrm{GEM}$ ratio is $1.97 \mathrm{E}-04$. The simulated ratio of $\mathrm{PM} / \mathrm{GEM}$ is low compared to observed ratio because of underestimation of simulated particulate mercury concentration. The simulated ratio pattern follows the observed ratio pattern for month of April 2002.

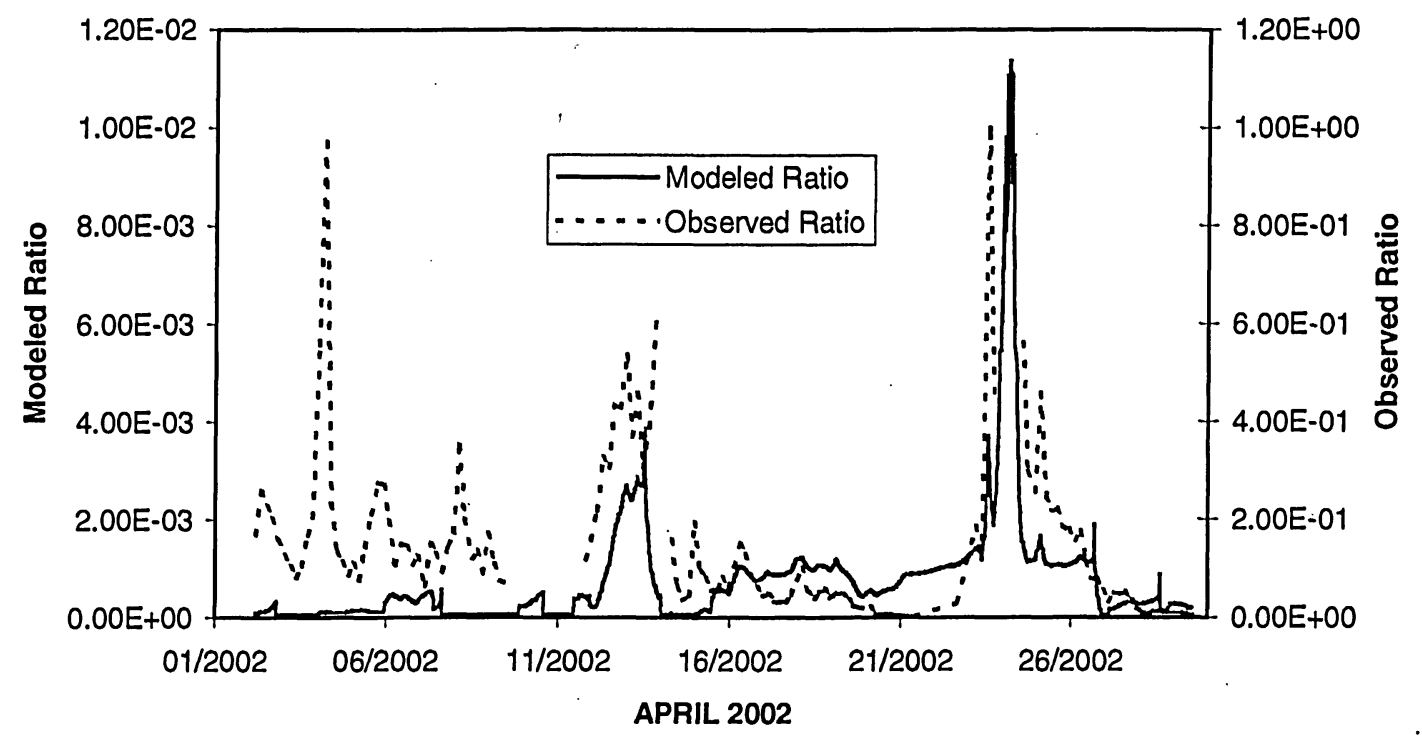

Figure 4.7 Simulated and Observed ratio of PM/GEM

Fig. 4.8 compares the modeled ratio of PM/RGM with observed ratio for spring month of April 2002. The average observed ratio of PM/RGM is 5.84 , whereas the calculated $\mathrm{PM} / \mathrm{RGM}$ ratio is 1.66 . For observed ratio of PM/RGM at alert, it has been observed that PM > RGM during and shortly after mercury depletion event. This ratio may depend upon the relative formation of reactive gaseous mercury species and also on different meteorological condition prevailing at various arctic monitoring sites (Schroeder and Steffen 2003). The modeled ratio of PM/RGM is very low in comparison with observed ratio because of underestimation of both RGM and PM concentrations. 


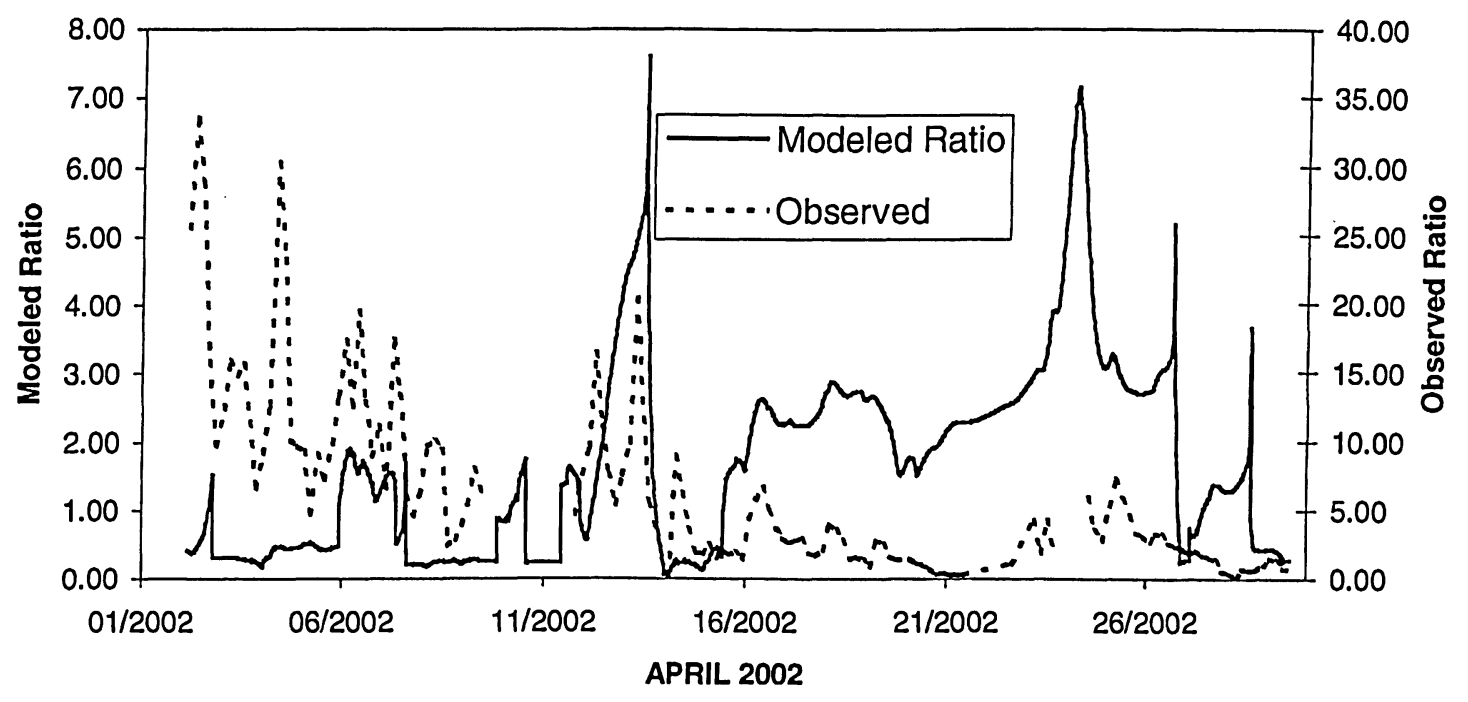

Figure 4.8 Simulated and Observed ratio of PM/RGM

\subsubsection{Dry deposition}

The simulated average dry deposition of RGM is $4.05 \mathrm{E}-03 \mathrm{ng} / \mathrm{m}^{2}-\mathrm{hr}$, whereas the simulated average dry deposition of particulate mercury (PM) is $4.78 \mathrm{E}-02 \mathrm{ng} / \mathrm{m}^{2}-\mathrm{hr}$. No measurements data of dry deposition flux were available for same month to compare with the simulated data. Schroeder et al. (1998) estimated an average springtime drydeposition flux for mercury of $2.5 \pm 0.5 \mathrm{ng} / \mathrm{m}^{2}-\mathrm{hr}$. The simulated dry deposition flux of reactive gaseous mercury is very low compared to this dry deposition flux. The underestimation of dry deposition flux of reactive gaseous mercury may be due to very low concentration of RGM, which is due to very low conversion of GEM to RGM. The simulated average dry deposition velocity of reactive gaseous mercury was $0.7 \mathrm{~cm} / \mathrm{sec}$.

It has been observed that divalent gaseous mercury is highly reactive and also efficiently removed by dry deposition whereas particulate mercury is removed from the atmosphere slowly. Observed results indicate higher concentrations and a longer lifetime of 
$\operatorname{Hg}(\mathrm{p})(\sim 1$ week) compared to divalent mercury ( 1 day) (Schroeder et al. 1998). In the simulated results, dry deposition of particulate mercury is higher compared to reactive gaseous mercury. The simulated average dry deposition velocity for particulate mercury was $4.75 \mathrm{~cm} / \mathrm{sec}$, which is very high compared to simulated average dry deposition velocity of reactive gaseous mercury. The possible reason of overestimation of dry deposition for particular mercury may be using the average dry deposition velocity of sulfate particles and non-distribution of particulate mercury into different size intervals.

\subsubsection{Wet deposition}

$\mathrm{Hg}$ in snow is present in both the dissolved and the particulate phases. The main mechanisms for the wet removal of $\mathrm{Hg}$ from the atmosphere is snow fall of water soluble or particulate forms of $\mathrm{Hg}$ and Oxidation of $\mathrm{Hg}^{0}$. Wet deposition is derived by summing up the product of concentration of all aqueous species $(A Q(1)-A Q(10))$ in Fig. 3.2. The average wet deposition simulated by model is $1.43 \mathrm{ng} / \mathrm{m}^{2}-\mathrm{hr}$. There were no observed data of wet deposition to compare with the simulated wet deposition flux. 


\section{Chapter 5}

\section{Sensitivity Analysis}

\subsection{Introduction}

The atmospheric chemistry of mercury is influenced by many chemical and physical processes and the transformation among the three major species: GEM, RGM and PM (Pleijel and Munthe, 1995). Besides washing out particulate $\mathrm{Hg}(\mathrm{p})$, clouds are also the media of oxidizing elemental $\mathrm{Hg}$ to more soluble forms. This transformation involves ozone and soot particles. In addition to this well-known oxidation, reduction and adsorption mechanism Munthe (1992), Lamborg and Fitzgerald (1996) suggested that $\mathrm{Hg}$ in precipitation is primarily due to particle incorporation. They also pointed out that gas phase $\mathrm{Hg}$ is transferred to particle phase during transport.

This chapter reports results of a sensitivity analysis to examine the dry and wet depositions in response to changes in concentration of secondary pollutants. Major questions to answer included: 1). What is the impact of atmospheric chemistry, for example, ozone concentration and soot concentration, on $\mathrm{Hg}$ deposition?

\subsection{Sensitivity analysis}

Simulations were conducted using the model described in chapter 3 for the spring month of 2002. The model input and meteorological conditions for the month of April 2002 simulations are described in chapter 4. 
For the sensitivity analysis, the default conditions for the month of April 2002 described in 4.2 were used as the base case. Additional simulations were conducted for the same month, April 2002 by changing one parameter at a time as listed in table 5.1.

Table 5.1 Conditions used in sensitivity study

Conditions and parameters $\quad$ Value

Ambient ozone concentration

$35 \mathrm{ppb}$ to $50 \mathrm{ppb}$

Ambient soot concentration

$1.0 \mathrm{ppb}$ to $0.5 \mathrm{ppb}$

For simulations with parameter change applied to the Canadian arctic, the dry and wet deposition were calculated and compared with those of the base case.

\subsection{Results of the sensitivity analysis}

\subsubsection{Dry deposition}

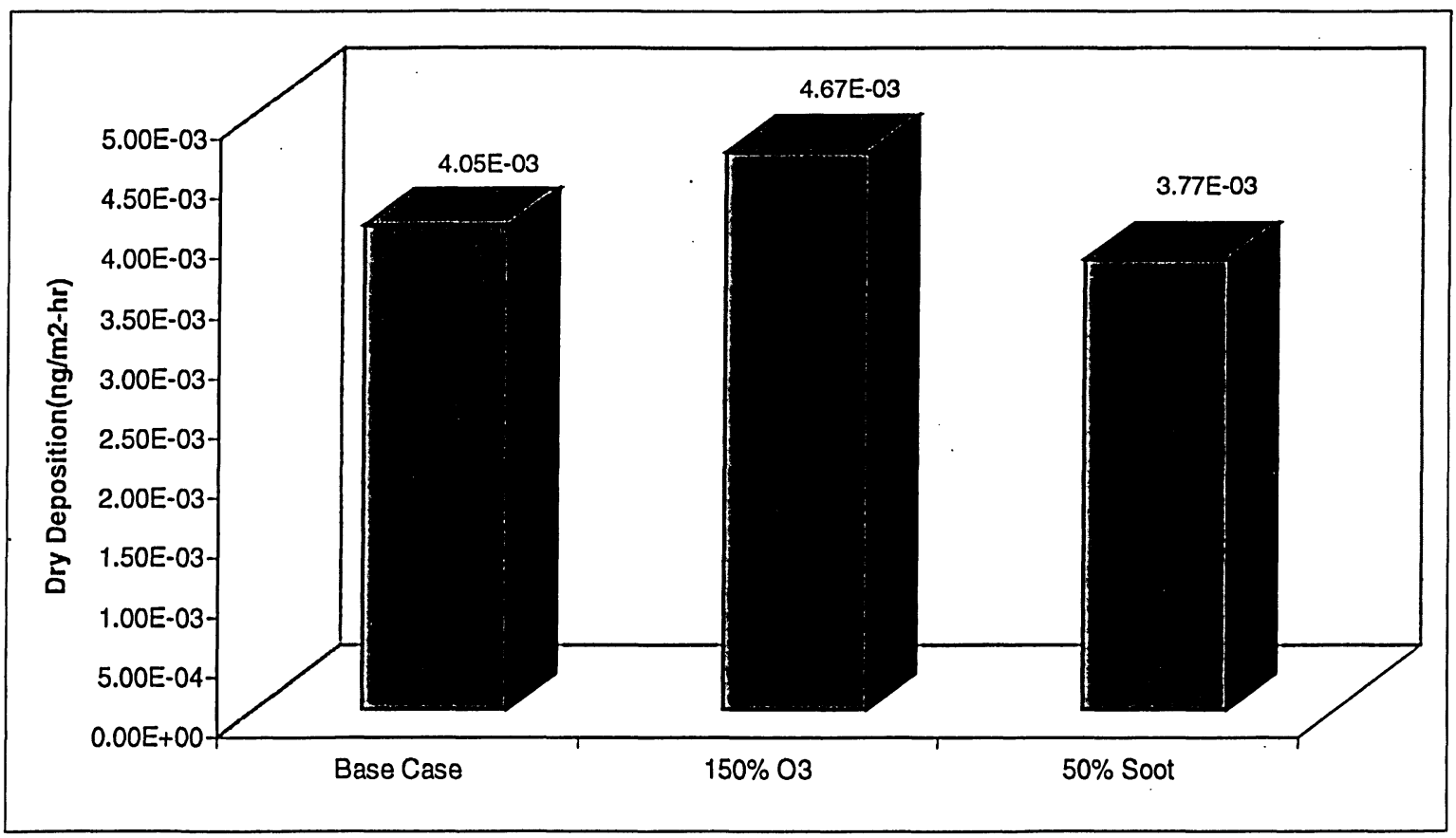

Figure 5.1 RGM Dry deposition for the base case and conditions listed in Table 5.1 
Fig. 5.1 compares the dry deposition of reactive gaseous mercury in the base case and under each of the conditions listed in Table 5.1.

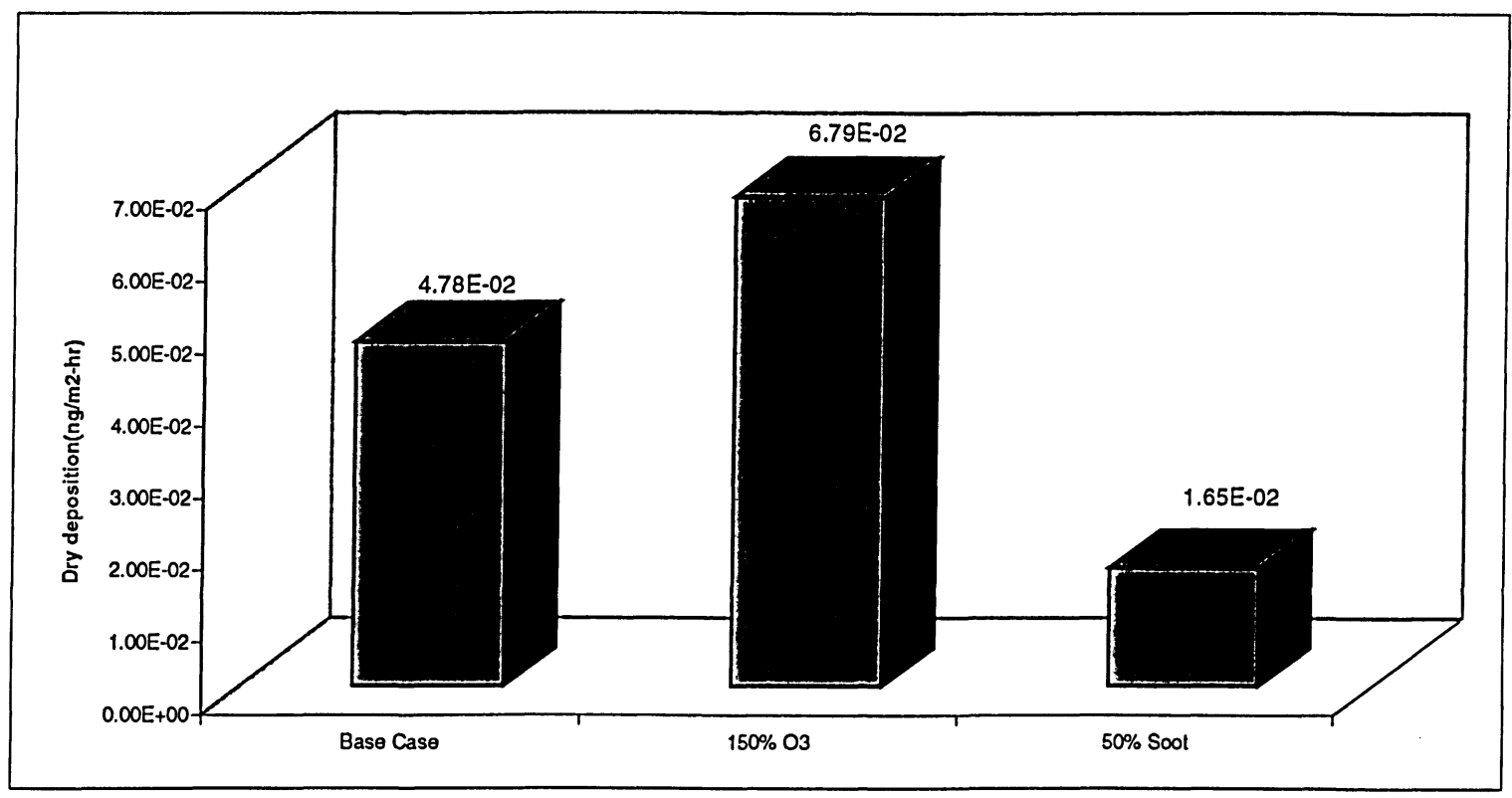

Figure 5.2 PM Dry deposition for the base case and conditions listed in Table 5.1

Fig. 5.2 compares the dry deposition of particulate mercury in the base case and under each of the conditions listed in Table 5.1. The dry deposition of both RGM and PM increased with increasing ozone concentration and decreased with decreasing soot concentration. As ozone concentration increases, there is more conversion of GEM to RGM and subsequent more dry deposition of RGM.

\subsubsection{Wet deposition}

Fig. 5.3 compares the wet deposition of $\mathrm{Hg}$ in the base case and under each of the conditions listed in Table 5.1. Compared with the base case, wet deposition increased with increasing ozone concentration and decreased with decreasing soot concentration. 
Wet deposition is sensitive to ambient concentrations of ozone and soot particles because of their direct impact on the aqueous chemical reaction.

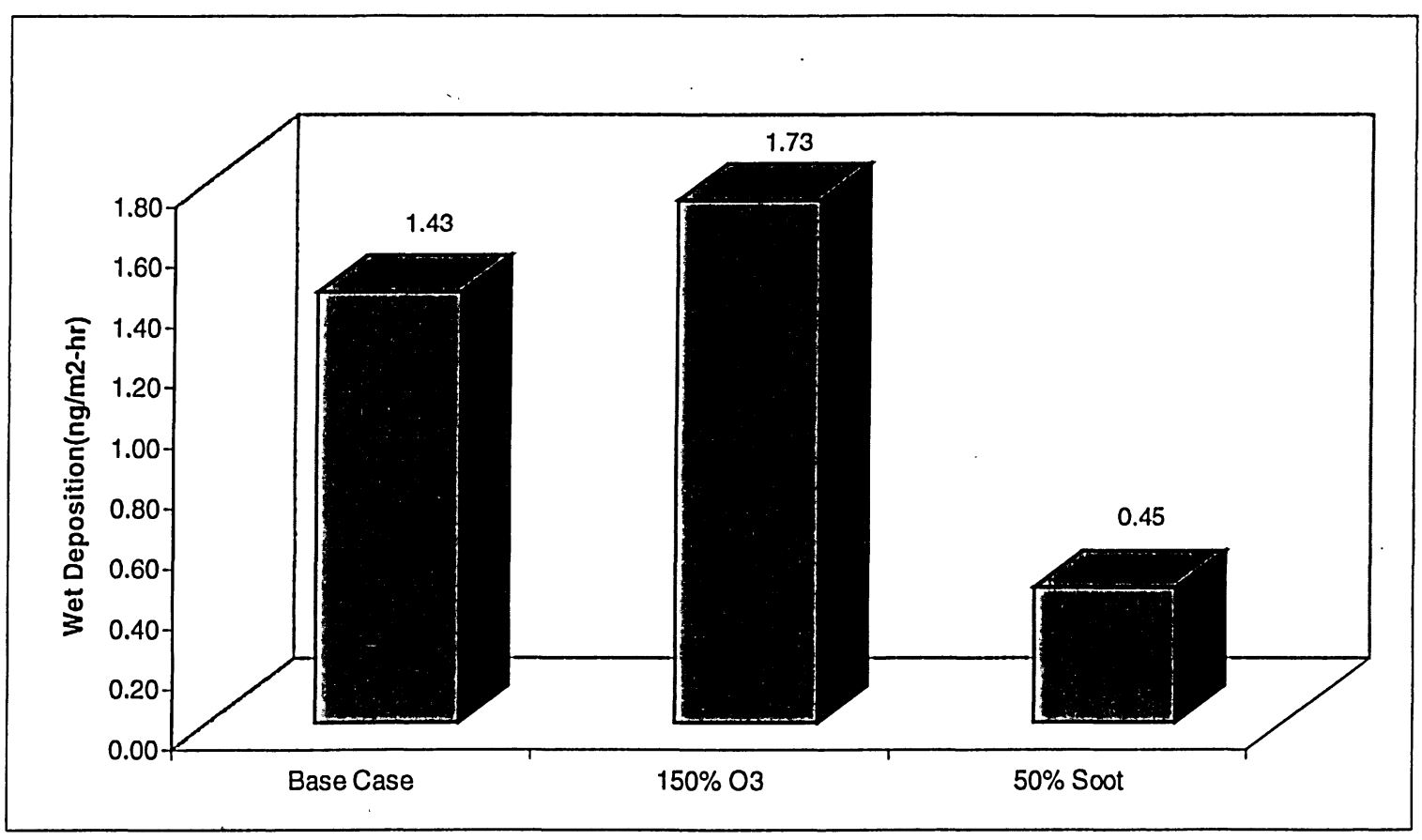

Figure 5.3 Wet depositions for the base case and conditions listed in Table 5.1

From the sensitivity analysis, it can be inferred that both dry and wet deposition of mercury is sensitive to ambient concentrations of ozone and soot particles. 


\section{Chapter 6}

\section{Summary, Conclusions and Recommendations}

\subsection{Summary of the study}

This thesis presents a systematic study on the transformation and deposition of atmospheric Hg. By incorporating mercury chemistry module into one-dimensional climate model (LCM/FIZ-C), the newly developed model was capable of simulating the atmospheric chemistry of mercury. The model takes meteorological parameters and emission data, and is capable of predicting $\mathrm{Hg}$ concentrations and deposition. The simulation results for $\mathrm{Hg}$ in Canadian Arctic after polar sunrise in 2002 were compared with available monitoring data from Meteorological Services of Canada, Downsview, Ontario. The model simulations agree reasonably with measured values with some underestimation probably caused by lower conversion of GEM into RGM. The model was tested for sensitivity by varying the ozone concentration from $35 \mathrm{ppb}$ to $50 \mathrm{ppb}$ and soot concentration from $1.0 \mathrm{ppb}$ to $0.5 \mathrm{ppb}$. The sensitive analysis indicated that the $\mathrm{Hg}$ deposition was sensitive to ambient concentrations of ozone and soot particles because of their direct impact on the aqueous chemical reaction.

\subsection{Concluding remarks}

The aim of this work was to simulate a specific measurement event and to advance the understanding of the arctic atmospheric mercury chemistry. The column model used in this study serves as a complement to large-scale model which include much more 
dynamical processes. The result can be used as a base resource for the development of condensed atmospheric chemistry. The greatest limitation of column models is that the physical processes occurring inside the model air column cannot be coupled interactively with its environment. Regional scale models are very useful tools for investigating episodic situations.

Most likely, just atmospheric pathways are responsible for elevated $\mathrm{Hg}$ concentrations in the arctic environment. The processed involved in mercury depletion events are yet to be identified but the observed rapid fluctuations in gaseous mercury concentration coincide with ozone depletion events indicating that halogen containing radicals are involved. During tropospheric ozone depletion periods, it has been suggested that halogens (or other oxidants) convert $\mathrm{Hg}(0)$ to $\mathrm{Hg}(\mathrm{II})$, resulting in reaction products, which are much less volatile than $\operatorname{Hg}(0)$ and more readily deposited from the atmosphere to polar ecosystems.

For dry deposition, there are no direct measurements of the dry deposition velocities of reactive gaseous mercury and particulate mercury. Uncertainties in deposition velocities directly affect the deposition patterns of mercury species.

\subsection{Regulation concern}

Modeling studies confirmed that $\mathrm{Hg}$ pollution is a global problem. It is obvious that emissions must be reduced to ease the $\mathrm{Hg}$ burden on the atmosphere and the aqueous ecosystems. In addition to applying air pollution control devices, emissions can be cut at the source end. For example, reduce the use of mercury in batteries, light bulbs, laboratory supplies and paint; and reuse and recycle municipal waste. On the other hand, one needs to recognize that it is not the $\mathrm{Hg}$ in the air, but the methyl mercury in fish that 
poses environmental concerns. Thus, it may be equally important to understand the influence of changing atmospheric chemistry, for example, ozone concentration, on the removal of atmospheric $\mathrm{Hg}$. It is also very important to understand the formation of $\mathrm{MeHg}$ and the pathways of $\mathrm{Hg}$ to water bodies, for example, higher aqueous $\mathrm{Hg}$ concentrations associated with peak flow and snowmelt.

\subsection{Recommendations for future studies}

The study described in this thesis represents one of the attempts to synthesize the current knowledge of mercury into a system that can be used to understand the local atmospheric transport and fate of mercury. It is important to note that much of knowledge regarding the arctic chemistry of mercury is relatively recent and hypothetical. This knowledge is expected to improve as additional research is performed over the coming years. Other improvements to the model such as more grid points and its inputs are expected to lead to a better understanding of the atmospheric processes that govern the mercury depletion event observed at Canadian arctic.

The primary objective of using CAM with mercury chemistry module was to use the seasalt aerosol of CAM to simulate the gas-particle partitioning of mercury during mercury depletion events(MDE), as sea-salt plays a major role in the depletion of mercury after polar sunrise. Due to shortage of time, this thesis does not represent this study. There is more modeling work such as gas-particle partitioning of mercury, inclusion of halogenmercury chemistry and transport of mercury need to be done in order to simulate the mercury depletion events more accurately. More experimental work in understanding mercury chemical mechanism during springtime arctic depletion and measurement studies for model evaluations is also needed. 


\section{REFERENCES}

AMAP. AMAP Assessment Report: Arctic Pollution Issues. 1998. Arctic Monitoring and Assessment Programme. AMAP, Oslo, Norway. Xii+859 pp.

Bergan T., Sekkesaeter S., Steinnes E., Valdal A. and Wibetoe G. 2003. Springtime depletion of mercury in the European Arctic as observed at Svalbard. The Science of the Total Environment 304, 43-51.

Bergan T. and Rodhe H. 2001. Oxidation of Elemental Mercury in the Atmosphere; Constraints imposed by Global Scale Modeling. Journal of Atmospheric Chemistry 40, 191-212.

Bergan T., Gallardo L. and Rodhe H. 1999. Mercury in the global atmosphere: a three -dimensional model study. Atmospheric Environment 33, 1575-1585.

Blanchet J. P., Bourque A. and Therrien D. 1996. A physically based Local Climate Model: LCMii. Atmosphere-Ocean.

Brosset C. 1987. Water, Air and Soil pollution 34, 145-166.

Bullock O.R. and Breheme K.A. 2002. Atmospheric mercury simulation using the CMAQ model: formulation, description and analysis of wet deposition results. Atmospheric Environment 36, 2135-2146.

Bullock Jr. O.R., Benjey W.G. and Keating M.H. 1997. The modeling of regionalscale atmospheric mercury transport and deposition using RELMAP. 323-347.

Chu P. and Porcella D.B. 1995. Mercury stack emissions from U.S. electric utility power plants. Water, Air and Soil Pollution. 80, 135-144.

Dastoor A. P. and Larocque Y. 2004. Global circulation of atmospheric mercury: a modeling study. Atmospheric Environment 38, 147-161.

Fitzgerald W.F. 1995. Is mercury increasing in the atmosphere? The need for an atmospheric mercury network. Water, Air and Soil Pollution. 80, 245-254.

Fitzgerald W.F., Engstrom D.R., Mason R.P. and Nater E.A. 1998. The case for atmospheric mercury contamination in remote area. Environmental Science and Technology 32(1), 1-7.

Gerber F. and Seinfeld J.H. 1985. Relative-humidity parameterization of the Navy aerosol model(NAM). NRL Rep. 8956, National Research Lab, Washington, D.C. 
Gong S.L., Barrie L.A. and Blanchet J.P. 1997. Modeling sea-salt aerosols in the atmosphere 1. Model Development. Journal of Geophysical Research 102(D3), 38053818.

Gong S. L., Barrie L. A., Blanchet J. P., Salzen V., Lohmann U., Lesins G., Spacek L., Zhang L. M., Girrard E., Lin H., Leaitch R., Leighton H., Chylek P. and Huang P. 2003. Canadian Aerosol Module: A size-segregated simulation of atmospheric aerosol processes for climate and air quality models 1 . Module development. Journal of Geophysical Research 108(D1).

Hall B. 1995. The gas phase oxidation of elemental mercury by ozone. Water, Air and Soil pollution. $80,301-315$.

http://www.ec.gc.ca/mercury 1999

http://wi.water.usgs.gov/pubs 1995

http://www.frontiergeosciences.com/ 2002

Iverfeldt A. and Lindqvist O. 1986. Atmospheric oxidation of elemental mercury by ozone in the aqueous phase. Atmospheric Environment 20, 1567-1573.

Iverfeldt A., Munthe J. and Hultberg H. 1991. Occurrence and turnover of atmospheric mercury over the Nordic countries. Water, Air and Soil pollution. 56, 251-265.

Jacobson M. 1999. Fundamentals of Atmospheric Modeling, Cambridge University Press.

Lamborg C.H. and Fitzgerald W.F. 1996. Modeling the atmospheric chemistry of mercury using naturally occurring, particle-reactive radionuclides. Book of Abstracts. Fourth International Conference on Mercury as a Global Pollutant. Eds.: Ebinghaus R., Peterson G. and Tumpling U. Germany.

Lamborg C.H., Fitzgerald W.F., O'Donnnell J. and Torgersen T. 2002. A non-steadystate compartmental model of global-scale mercury biogeochemistry with interhemispheric atmospheric gradients. Geochimica et Cosmochimica Acta 66(7), 1105-1118.

Lin C. J. and Pehkonen S.O. 1997. Aqueous free radical chemistry of mercury in the presence of iron oxides and ambient aerosol. Atmospheric Environment 31, 41254137.

Lin C. J. and Pehkonen S.O. 1999. The Chemistry of atmospheric mercury : a review. Atmospheric Environment 33, 2067-2079. 
Lin C.J. and Pehkonen S.O. 1998a. Two-phase model of mercury chemistry in the atmosphere. Atmospheric Environment. 32, 2543-2558.

Lin C. J. and Pehkonen S.O. 1998. Oxidation of elemental mercury by aqueous chlorine (HOCl/OCl-) : Implications for tropospheric mercury chemistry. Journal of Geophysical research 103(D21), 28,093-28,102.

Lindberg S.E. 1987. Mercury. In Lead, Mercury, Cadmium and Arsenic in the Environment. Eds.: Hutchinson T.C. and Meema K.M. John Wiley \& Sons. New York.

Lindberg S.E., Brooks S., Lin C.J., Meyers T., Chambers L., Landis M. and Stevens R. 2001. Formation of reactive gaseous mercury in the Arctic: Evidence of oxidation of $\mathrm{Hg} 0$ to gas-phase $\mathrm{Hg}$ (II) compounds after Arctic Sunrise. Water, Air, Soil Pollution Focus 1, 295-302.

Lindberg S.E., Brooks S., Lin C.J., Scott K.J., Landis M.S., Stevens R.K., Goodsite M. and Richter A. 2002. Dynamic oxidation of gaseous mercury in the arctic troposphere at polar sunrise. Environmental Science and Technology 36, 1245-1256.

Lindqvist O. and Rodhe H. 1985. Atmospheric Mercury - a review. Tellus 27B, 136159.

Lu J.Y., Schroeder W.H., Barrie L.A., Steffen A., Welch H., Martin K., Lochard L., Hunt R.V., Boila G. and Richter A. 2001. Magnification of atmospheric mercury deposition to Polar Regions in springtime: the link to tropospheric ozone depletion chemistry. Geophysical Research Letter 28(17), 3219-3222.

Munthe J. 1992. The aqueous oxidation of elemental mercury by ozone. Atmospheric Environment. 26A(8), 1461-1468.

Munthe J., Xiao Z.F. and Lindqvist O. 1991. The aqueous reduction of divalent mercury by sulfite. Water, Air, and Soil Pollution. 56, 612-630.

Munthe J. 1993. Mercury in the atmosphere - Emissions, Transformations, Deposition and Effects. Swedish Environmental Research Institute, Sweden.

Pai P., Karamchandani P. and Seigneur C. 1997. Simulation of the regional atmospheric transport and fate of mercury using a comprehensive Eulerian model. Atmospheric Environment. 31(17), 2717-2732.

Pai P., Karamchandani P., Seigneur C. and Allan M. Sensitivity of simulated atmospheric mercury concentrations and deposition to model input parameters. Journal of Geophysical Research 104, 13,855-13,868. 
Pehkonen S.O. and Lin C.J. 1998. Aqueous photochemistry of divalent mercury wit organic acids. Journal of air and waste management association. 48: 144-150.

Petersen G., Iverfeldt A. and Munthe J. 1995. Atmospheric mercury species over central and northern Europe. Model calculations and comparison with observations from the Nordic Air and Precipitation Network for 1987 and 1988. Atmospheric Environment. 29, 47-67.

Petersen G., Munthe J., Pleijel K., Bloxam R. and A.Vinod Kumar 1998. A comprehensive eulerian modeling framework for airborne mercury species : Development and Testing of the Tropospheric Chemistry Module(TCM). Atmospheric Environment 32(5), 829-843.

Petersen G., Bloxam R., Wong S., Munthe J., Kruger O., Schmolke S.R. and A.Vinod Kumar 2001. A comprehensive eulerian modeling framework for airborne mercury species : Model development and applications in Europe. Atmospheric Environment 35, 3063-3074.

Pirrone N., Glinsorn G. and Keeler G. J. 1995. Ambient levels and dry deposition fluxes of mercury to lakes Huron, Erie and St. Clair. Water, Air and Soil Pollution 80, 179-188.

Pirrone N., Keeler G. J. and Nriagu J. O. 1996. Regional differences in worldwide emissions of mercury to the atmosphere. Atmospheric Environment 30, 2981-2987.

Pleijel K. and Munthe J. 1995. Modeling the atmospheric mercury cycle - chemistry in fog droplets. Atmospheric Environment 29, 1441-1457.

P'yankov V.A. 1949. Kinetics of the reaction between mercury vapor and ozone. Zhur. Obshchev Khim.(J.Gen.Chem.) 19, 224-229.

Rudd J.W.M. 1995. Sources of Methyl mercury to the freshwater ecosystems : a review. Water, Air and Soil Pollution 80, 697-713.

Ryaboshapko A., Bullock R., Ebinghaus R., Ilyin I., Lohman K., Munte J., Petersen G., Seigneur C. and Wangberg I. 2002. Comparison of mercury chemistry models. Atmospheric Environment 36, 3881-3898.

Sakata M. and Marumoto K. 2002. Formation of atmospheric particulate mercury in the Tokyo metropolitan area. Atmospheric Environment. 36(2), 239-246.

Schroeder W.H. and Jackson R.A. 1987. Environmental measurements with an atmospheric mercury monitor having speciation capabilities. Chemosphere 16(1), 183-199. 
Schroeder W.H., Yarwood G. and Niki H. 1991. Transformation processes involving $\mathrm{Hg}$ species in atmosphere - results from a literature survey. Water, air and Soil Pollution 56, 653-666.

Schroeder W. H. and Munthe J. 1998. Atmospheric Mercury - an overview. Atmospheric Environment 32, 809-822.

Schroeder W. H., Anlauf K. G., Barrie L. A., Lu J. Y., Steffen A., Schneeberger D. R. and Berg T. 1998 Arctic springtime depletion of mercury. Nature 394, 331-332.

Schroeder W.H. and Steffen A. 2003. Conference report: First international arctic atmospheric mercury research workshop. Atmospheric Environment 37, 2551-2555.

Seigneur C., Wrobel J. and Constantinou E. 1994. A chemical kinetic mechanism for atmospheric inorganic mercury. Environmental Science and Technology 28, 15891597.

Seigneur C., Karamchandani P., Lohman K. and Vijayraghavan K. 2001. Multiscale modeling of the atmospheric fate and transport of mercury. Journal of Geophysical Research 106 (D21), 27795-27809.

Shannon J.D. and Voldner E.C. 1995. Modeling atmospheric concentrations of mercury and deposition to the Great Lakes. Atmospheric Environment. 29, 16491661.

Slemer F., Schuster G. and Seiler W. 1985. Distribution, speciation and budget of atmospheric mercury. Journal of atmospheric chemistry 3, 407-434.

Stein E. D., Cohen Y. and Winer A. M. 1996. Environmental distribution and transformation of mercury compounds. Environmental Science and Technology 26(1), 1-43.

Wilken 2001. Mercury in the Environment : Global Scenario as a frame for regional scenarios. ESWE Institute, Sweden.

Xiao Z.F., Munthe J., Schroeder W.H. and Lindqvist O. 1991. Vertical fluxes of volatile $\mathrm{Hg}$ over forest soil and lake surfaces in Sweden. Tellus. 43B, 267-279.

Xiao Z.F., Munthe J., Stromberg D. and Lindqvist O. 1994. Photochemical behavior of inorganic $\mathrm{Hg}$ compounds in aqueous solution. Mercury as a global pollutant Integration and synthesis. Lewis publishers, 581-592.

Xu X., Yang X., Miller D. R., Helble J..J. and Carley R. J. 2000. A regional scale modeling study of atmospheric transport and transformation of mercury I. Model development and evaluation. Atmospheric Environment 34, 4933-4944. 
Xu X., Yang X., Miller D. R., Helble J. J. and Carley R. J. 1999 Formulation of bidirectional atmosphere-surface exchanges of elemental mercury. Atmospheric Environment 33, 4345-4355.

Young T.R. and Boris J.P. 1977. A numerical technique for solving stiff ordinary differential equations associated with the chemical kinetics of reactive flow problems, Journal of Physical chemistry 81, 2424-2427. 


\section{APPENDIX A}

Reaction rate constant for Mercury chemistry used in Modeling (Petersen et al. 1998)

\begin{tabular}{|c|c|c|c|}
\hline $\begin{array}{l}\text { Sr. } \\
\text { No. }\end{array}$ & & Reaction & $\begin{array}{l}\text { Rate } \\
\text { Constant } \\
\text { Sec }^{-1}\end{array}$ \\
\hline 1 & $\mathrm{R}(1)$ & {$\left[\mathrm{Hg}^{0}\right]$ gas $\quad \mathrm{G}(1) \rightarrow\left[\mathrm{Hg}^{0}\right] \mathrm{aq}$} & $3.15 \mathrm{E}-02$ \\
\hline 2 & $\mathrm{R}(2)$ & $\begin{array}{lll}\left.\mathrm{Hg}^{0}\right] \mathrm{aq} & \mathrm{AQ}(1) \rightarrow\left[\mathrm{Hg}^{0}\right] \text { gas } & \mathrm{G}(1)\end{array}$ & $5.99 \mathrm{E}+03$ \\
\hline 3 & $\mathrm{R}(3)$ & {$\left[\mathrm{HgCl}_{2}\right]$ gas $\mathrm{G}(2) \rightarrow\left[\mathrm{HgCl}_{2}\right.$ (dissolved)]aq $\mathrm{AQ}(2)$} & $2.91 \mathrm{E}-02$ \\
\hline & $\mathrm{R}(3)$ & {$[\mathrm{HgO}]$ gas $\quad \mathrm{G}(4) \rightarrow[\mathrm{HgO}($ dissolved $)] \mathrm{aq} \quad \mathrm{AQ}(4)$} & $2.91 \mathrm{E}-02$ \\
\hline 4 & $\mathrm{R}(4)$ & {$\left[\mathrm{HgCl}_{2}\right.$ (dissolved)]aq $\mathrm{AQ}(2) \rightarrow\left[\mathrm{HgCl}_{2}\right]$ gas $\mathrm{G}(2)$} & $5.35 \mathrm{E}-04$ \\
\hline & $\mathrm{R}(4)$ & {$[\mathrm{HgO}($ dissolved)]aq $\mathrm{AQ}(4) \rightarrow[\mathrm{HgO}] \mathrm{gas} \quad \mathrm{G}(4)$} & $5.35 \mathrm{E}-04$ \\
\hline 5 & $\mathrm{R}(5)$ & {$[\mathrm{Hg}($ particulate $)]$ gas $\mathrm{G}(3) \rightarrow[\mathrm{Hg}$ (particulate) $] \mathrm{aq} \quad \mathrm{AQ}(3)$} & Varies \\
\hline 6 & $\mathrm{R}(6)$ & $\begin{array}{l}{\left[\mathrm{Hg}^{0}\right] \mathrm{aq} \mathrm{AQ}(1)+\mathrm{O}_{3} \rightarrow\left[\mathrm{HgO}(\text { dissolved) }] \mathrm{aq} \mathrm{AQ}(4)+\mathrm{O}_{2}\right.} \\
\mathrm{k}=4.7 \mathrm{E}+07 \mathrm{M}^{-1} \mathrm{~S}^{-1} \text { (Munthe,1992) }\end{array}$ & $3.95 \mathrm{E}-02$ \\
\hline 7 & $\mathrm{R}(7)$ & $\begin{array}{l}{\left[\mathrm{HgO}(\text { dissolved) }] \mathrm{aq} \mathrm{AQ}(4) \rightarrow\left[\mathrm{Hg}^{0}\right] \mathrm{aq} \mathrm{AQ}(1)\right.} \\
\mathrm{k}=0.4 \mathrm{E}-03 \mathrm{~S}^{-1} \text { (Munthe et al. 1991) }\end{array}$ & $4.00 \mathrm{E}-04$ \\
\hline 8 & $\mathrm{R}(8)$ & $\begin{array}{l}{\left[\mathrm{Hg}^{0}\right] \mathrm{aq} \mathrm{AQ}(1) \rightarrow\left[\mathrm{Hg}\left(\mathrm{SO}_{3}\right)_{2}{ }^{2-} \text { (dis.) }\right] \mathrm{aq} \mathrm{AQ}(7)} \\
\mathrm{k}=0.1 \mathrm{E}-14 \mathrm{~S}^{-1} \text { (Petersen et al. 1998) }\end{array}$ & $1.00 \mathrm{E}-15$ \\
\hline 9 & $\mathrm{R}(9)$ & $\begin{array}{l}{\left[\mathrm{Hg}\left(\mathrm{SO}_{3}\right)_{2}{ }^{2-} \text { (dis.)]aq } \mathrm{AQ}(7) \leftarrow \rightarrow \mathrm{HgSO}_{3}+\mathrm{SO}_{3}{ }^{2-}\right.} \\
(\mathrm{Rate} \text { Limiting Step) } \\
\mathrm{k}=4.4 \mathrm{E}-04 \mathrm{~S}^{-1} \text { (Petersen et al. 1998) } \\
\mathrm{HgSO}_{3} \rightarrow\left[\mathrm{Hg}^{0}\right] \text { aq } \mathrm{AQ}(1)+\text { Products } \\
\mathrm{k}=0.6 \mathrm{~S}^{-1} \text { (Munthe et al. 1991) }\end{array}$ & $4.40 \mathrm{E}-04$ \\
\hline 10 & $\mathrm{R}(10)$ & $\begin{array}{l}{[\mathrm{HgO}] \mathrm{aq} \mathrm{AQ}(4)+\mathrm{H}^{+} \rightarrow\left[\mathrm{Hg}^{2+}\right] \text { aq } \mathrm{AQ}(8)+\mathrm{OH}^{-}} \\
\mathrm{k}=1 \mathrm{E}+10 \mathrm{M}^{-1} \mathrm{~S}^{-1}(\text { Pleijel and Munthe } 1995)\end{array}$ & $3.30 \mathrm{E}+05$ \\
\hline 11 & $\mathrm{R}(11)$ & $\begin{array}{l}{\left[\mathrm{Hg}^{2+}\right] \text { aq AQ(8) } \rightarrow[\mathrm{HgO}] \text { aq } \mathrm{AQ}(4)} \\
\mathrm{k} 11=0.4 \mathrm{~S}^{-1}\end{array}$ & $4.00 \mathrm{E}-01$ \\
\hline
\end{tabular}




\begin{tabular}{|c|c|c|c|}
\hline 12 & $\mathrm{R}(12)$ & {$\left[\mathrm{Hg}\left(\mathrm{SO}_{3}\right)_{2}{ }^{2-}\right] \mathrm{aq} \mathrm{AQ}(7) \rightarrow\left[\mathrm{Hg}^{2+}\right] \mathrm{aq} \mathrm{AQ}(8)$} & $8.55 \mathrm{E}-28$ \\
\hline 13 & $\mathrm{R}(13)$ & $\begin{array}{l}{\left[\mathrm{Hg}^{2+}\right] \mathrm{aq} \mathrm{AQ}(8)+2\left[\mathrm{SO}_{3}{ }^{2-}\right] \rightarrow\left[\mathrm{Hg}\left(\mathrm{SO}_{3}\right)_{2}{ }^{2-}\right] \mathrm{aq} \mathrm{AQ}(7)} \\
\mathrm{k}=1 \mathrm{E}+15 \mathrm{M}^{-2} \mathrm{~S}^{-1} \text { Petersen et al. } 1998\end{array}$ & $1.00 \mathrm{E}-03$ \\
\hline 14 & $\mathrm{R}(14)$ & $\begin{array}{l}{\left[\mathrm{Hg}^{2+}\right] \mathrm{aq} \mathrm{AQ}(8)+2 \mathrm{Cl}^{-} \rightarrow\left[\mathrm{HgCl}_{2}\right] \mathrm{aq} \mathrm{AQ}(2)} \\
\mathrm{k}=1 \mathrm{E}+15 \mathrm{M}^{-2} \mathrm{~S}^{-1} \text { Petersen et al. } 1998\end{array}$ & $1.00 \mathrm{E}+03$ \\
\hline 15 & $\mathrm{R}(15)$ & $\mathrm{HgCl}_{2}(\mathrm{aq}) \mathrm{AQ}(2) \rightarrow\left[\mathrm{Hg}^{2+}\right] \mathrm{aq} \mathrm{AQ}(8)+2 \mathrm{Cl}^{-}$ & $6.024 \mathrm{E}-15$ \\
\hline 16 & $\mathrm{R}(16)$ & $\begin{array}{l}{\left[\mathrm{Hg}^{2+}\right] \mathrm{aq} \mathrm{AQ}(8)+\mathrm{OH}^{-} \rightarrow \mathrm{HgOH}^{+}} \\
\mathrm{HgOH}^{+}+\mathrm{Cl}^{-} \rightarrow[\mathrm{HgOHCl}(\text { dis. })] \text { aq } \mathrm{AQ}(9) \\
\text { k16 }=1 \mathrm{E}+15 \mathrm{M}^{-2} \mathrm{~S}^{-1} \text { Petersen et al. } 1998\end{array}$ & $6.32 \mathrm{E}-01$ \\
\hline 17 & $\mathrm{R}(17)$ & $\begin{array}{l}{\left[\mathrm{HgOHCl}(\text { dis.) }] \text { aq } \mathrm{AQ}(9) \rightarrow \mathrm{HgOH}^{+}+\mathrm{Cl}^{-}\right.} \\
\mathrm{HgOH}^{+} \rightarrow\left[\mathrm{Hg}^{2+} \text { (dis.)]aq } \mathrm{AQ}(8)+\mathrm{OH}^{-}\right.\end{array}$ & $2.00 \mathrm{E}-18$ \\
\hline \multirow[t]{3}{*}{18} & $\mathrm{R}(18)$ & {$\left[\mathrm{Hg}\left(\mathrm{SO}_{3}\right)_{2}{ }^{2-}\right.$ (dis.)]aq AQ(7) $\rightarrow \mathrm{HgII}($ ad.) $\mathrm{AQ}(10)$} & $2.00 \mathrm{E}-02$ \\
\hline & $\mathrm{R}(18)$ & {$[\mathrm{HgOHCl}($ dis.) $] \mathrm{aq} \mathrm{AQ}(9) \rightarrow \mathrm{HgII}(\mathrm{ad}.) \mathrm{AQ}(5)$} & $2.00 \mathrm{E}-02$ \\
\hline & $\mathrm{R}(18)$ & {$\left[\mathrm{HgCl}_{2}\right.$ (dis.)]aq AQ(2) $\rightarrow \mathrm{HgII}(\mathrm{ad}.) \mathrm{AQ}(6)$} & $2.00 \mathrm{E}-02$ \\
\hline \multirow[t]{3}{*}{19} & $\mathrm{R}(19)$ & $\mathrm{HgII}(\mathrm{ad}.) \mathrm{AQ}(10) \rightarrow\left[\mathrm{Hg}\left(\mathrm{SO}_{3}\right)_{2}{ }^{2-}\right.$ (dis.) $]$ aq $\mathrm{AQ}(7)$ & $4.00 \mathrm{E}-02$ \\
\hline & $\mathrm{R}(19)$ & $\mathrm{HgII}($ ad.) $\mathrm{AQ}(5) \rightarrow[\mathrm{HgOHCl}$ (dis.)]aq $\mathrm{AQ}(9)$ & $4.00 \mathrm{E}-02$ \\
\hline & $\mathrm{R}(19)$ & $\mathrm{HgII}\left(\mathrm{ad}\right.$.) $\mathrm{AQ}(6) \rightarrow\left[\mathrm{HgCl}_{2}\right.$ (dis.)]aq $\mathrm{AQ}(2)$ & $4.00 \mathrm{E}-02$ \\
\hline 20 & $\mathrm{R}(20)$ & $\begin{array}{l}{\left[\mathrm{Hg}^{0}\right] \text { gas } \mathrm{G}(1)+\mathrm{O}_{3} \rightarrow[\mathrm{HgO}] \text { gas } \mathrm{G}(4)+\mathrm{O}_{2}} \\
\mathrm{k}=0.739 \mathrm{E}-09 \mathrm{ppb}^{-1} \mathrm{~S}^{-1} \text { (Hall, 1995) }\end{array}$ & $2.59 \mathrm{E}-07$ \\
\hline 21 & $\mathrm{R}(21)$ & {$[\mathrm{HgO}]$ gas $\mathrm{G}(4) \rightarrow\left[\mathrm{Hg}^{0}\right]$ gas $\mathrm{G}(1)$} & $2.59 \mathrm{E}-11$ \\
\hline
\end{tabular}

